\title{
Tumor Necrosis Factor and Its Receptors Are Crucial to Control Mycobacterium bovis Bacillus Calmette-Guerin Pleural Infection in a Murine Model
}

\author{
Leslie Chavez-Galan, ${ }^{* \dagger}$ Dominique Vesin, ${ }^{\star}$ Noria Segueni, ${ }^{\ddagger}$ Pritha Prasad, * Raphaële Buser-Llinares, ${ }^{*}$ Guillaume Blaser, *
} Jean-Claude Pache, ${ }^{\S}$ Bernhard Ryffel, ${ }^{\ddagger}$ Valérie F.J. Quesniaux, ${ }^{\ddagger}$ and Irene Garcia*

\begin{abstract}
From the Department of Pathology and Immunology, ${ }^{*}$ Centre Medical Universitaire, University of Geneva Medical School, Geneva, Switzerland; the Laboratory of Integrative Immunology, ${ }^{\dagger}$ National Institute of Respiratory Diseases Ismael Cosio Villegas, Mexico City, Mexico; Experimental Molecular Immunology and Neurogenetics (UMR7355), ${ }^{\ddagger}$ University of Orléans and CNRS, Orléans, France; and the Division of Clinical Pathology, ${ }^{\S}$ University Hospital, Geneva, Switzerland
\end{abstract}

Accepted for publication May 31, 2016.

Address correspondence to Irene Garcia, Ph.D., Department of Pathology and Immunology, Centre Medical Universitaire, Faculty of Medicine, University of Geneva, 1, Rue MichelServet, Geneva 1211, Switzerland. E-mail: irene. garcia-gabay@unige.ch.

\begin{abstract}
Tumor necrosis factor (TNF) is crucial to control Mycobacterium tuberculosis infection, which remains a leading cause of morbidity and mortality worldwide. TNF blockade compromises host immunity and may cause reactivation of latent infection, resulting in overt pulmonary, pleural, and extrapulmonary tuberculosis. Herein, we investigate the roles of TNF and TNF receptors in the control of Mycobacterium bovis bacillus Calmette-Guerin (BCG) pleural infection in a murine model. As controls, wild-type mice and those with a defective CCR5, a receptor that is crucial for control of viral infection but not for tuberculosis, were used. BCG-induced pleural infection was uncontrolled and progressive in absence of TNF or TNF receptor 1 (TNFR1)/TNFR2 (TNFR1R2) with increased inflammatory cell recruitment and bacterial load in the pleural cavity, and heightened levels of pleural and serum proinflammatory cytokines and chemokines, compared to wild-type control mice. The visceral pleura was thickened with chronic inflammation, which was prominent in $\mathrm{TNF}^{-/-}$and TNFR1R2 ${ }^{-/-}$mice. The parietal pleural of TNF${ }^{-/}$and TNFR1R2 ${ }^{-/-}$mice exhibited abundant inflammatory nodules containing mycobacteria, and these mice developed nonresolving inflammation and succumbed from disseminated BCG infection. By contrast, $\mathrm{CCR}^{-/-}$mice survived and controlled pleural BCG infection as wild-type control mice. In conclusion, BCG-induced pleurisy was uncontrolled in the absence of TNF or TNF receptors with exacerbated inflammatory response, impaired bacterial clearance, and defective mesothelium repair, suggesting a critical role of TNF to control mycobacterial pleurisy. (Am J Pathol 2016, 186: 2364-2377; http://dx.doi.org/10.1016/j.ajpath.2016.05.015)
\end{abstract}

Tuberculosis (TB) remains a major health problem causing high morbidity and mortality worldwide. Although the pulmonary form is the most common form of TB infection, extrapulmonary $\mathrm{TB}$, including pleural $\mathrm{TB}$, accounts for almost one third of reported TB cases. ${ }^{1-3}$ Pleural TB is a frequent clinical problem with fluid and inflammatory cell accumulation in the pleural cavity after Mycobacterium tuberculosis infection. ${ }^{4} \mathrm{~TB}$ infection is controlled by a $\mathrm{T}$ helper 1-type immune response with a critical contribution, but a minority of infected individuals (5\% to $10 \%$ ) will develop active disease. Mycobacteria may remain latent but may be reactivated when host immunity declines. ${ }^{5}$ Pleural TB has been reported as either a primary TB infection or a result of reactivation of latent $\mathrm{TB}$ infection, which may be because of different factors, including tumor necrosis factor (TNF) blockade. ${ }^{5,6}$ TNF is an important cytokine involved in the pathogenesis of human inflammatory diseases, such as rheumatoid arthritis and Crohn's disease. Many studies using genetic models of TNF inactivation and treatment

Supported by the Swiss National Foundation for Scientific Research grants 310033-146833 and 310033-166662 (I.G.), Ligue Pulmonaire Genevoise, and CNRS and University of Orleans through International Associated Laboratory «TB IMMUNITY» (LIA N ${ }^{2} 236$ ), Le Studium, Orléans, France (research fellowship to I.G.), and the National Council of Science and Technology (CONACyT, 207760), Mexico (L.C.G.).

Disclosures: None declared. 
with TNF neutralizing molecules have provided evidence implicating TNF as a key factor in host protective immune responses against mycobacterial infections. Mouse models of experimental tuberculosis have shown impaired control of bactericidal mechanisms, defective granuloma formation, and an alteration of $\mathrm{T}$ helper 1-type immune responses in mice lacking TNF activity. ${ }^{7,8}$ Transmembrane TNF and soluble TNF mediate protective immunity through TNFR1, whereas TNFR2 down-regulates immune functions and both TNF receptors interact with lymphotoxin $\alpha$ (LT $\alpha$ ) produced by activated lymphocytes. ${ }^{8-11}$ In humans, it has been shown that TNF also plays a critical role in host defense and the clinical use of TNF inhibitors has revealed an increased risk for opportunistic infections, including TB reactivation and new TB infections. ${ }^{6}$ Most reactivated TB, in patients treated with TNF inhibitors, develop extrapulmonary TB, which often delays the diagnosis and adequate treatment. ${ }^{6,12}$ Several studies have noted that the proportion of extrapulmonary TB has increased from $16.4 \%$ in 2002 to $22.4 \%$ in 2011, but the causes so far have not been identified. ${ }^{3,13-15}$

CCR5, the receptor for regulated on activation normal $\mathrm{T}$ cell expressed and secreted (RANTES), macrophage inflammatory protein (MIP)- $1 \alpha$, and MIP- $1 \beta$, is an important chemokine receptor controlling cell recruitment in different pathological situations, including inflammation and viral infections. ${ }^{16}$ However, in contrast to TNF requirement for TB infection control, CCR5 has been shown to be dispensable, despite increased local lymphocytic recruitment, during pulmonary TB infection. ${ }^{17,18}$

Animal models of pleurisy using Mycobacterium bovis bacillus Calmette-Guerin (BCG) and heat-killed M. tuberculosis infections have shown recruitment of neutrophils, monocytes, eosinophils, and lymphocytes secreting cytokines and chemokines in the pleural spaces and participating to granuloma formation. ${ }^{19-23}$ In the present study, a mouse model of pleural $M$. bovis BCG infection has been used to analyze the immunopathology, cell recruitment, and accumulation of inflammatory mediators. Using mice deficient for TNF or for TNFR1 plus TNFR2, we studied the implication and outcomes of pleural mycobacterial disease in immunodeficient mice and compared them to the responses generated in normal mice and those lacking CCR5. We document the kinetics of BCGinduced pleurisy evolution, cell recruitment, pleural cytokine/chemokine production, and immunopathology of visceral and parietal pleural mesothelium. This study shows that TNF or TNF receptor deficiency is associated with exacerbation of proinflammatory cytokine and chemokine production, defective Bacillus killing, hyperplasia, and erosion of the visceral pleura, as well as nodularity of the parietal pleura.

\section{Materials and Methods}

Mice

C57BL/6 mice and $\mathrm{TNF}^{-/-}, 24$ TNFR1xTNFR2 (TNFR1R2 $^{-1-}$ ), and $\mathrm{CCR}^{-1-}$ (The Jackson Laboratory,
Bar Harbor, ME) were housed in the Transgenose Institute animal facility (Transgenose Institute animal facility, CNRS UPS44, Orleans, France). For infection with $M$. bovis BCG, adult mice ( 8 to 12 weeks old) were kept in a biohazard animal unit (Orleans, France). Experiments were approved by the Ethics Committee for Animal Experimentation of CNRS Campus Orleans (number CLE CNRS Campus Orleans 2012-1001).

\section{M. bovis BCG and CFUs}

Mycobacterium bovis BCG Pasteur strain 1173 P2 was grown in Middlebrook 7H9 broth containing ADC (Difco, France), and middle-log phase bacilli were washed and frozen aliquots kept at $-80^{\circ} \mathrm{C}$ and then used for pleural infection. Colony-forming units (CFUs) were evaluated in the pleural fluids at day 14 or 28 after infection and in spleen at day 28 after infection, as previously reported. ${ }^{25}$

\section{BCG-Induced Pleurisy}

Mycobacterial pleurisy was generated by intrapleural cavity injection of $10^{6}$ CFUs of BCG Pasteur in $100 \mu \mathrm{L}$ of saline, as previously reported. ${ }^{22,23,26}$ Injection into the lung parenchyma results in bilateral pneumothorax and death as mice have only one pleural cavity. ${ }^{26}$ Mice were monitored twice a week and sacrificed 14 or 28 days after infection or observed for survival analysis. Groups of naïve littermates referred as uninfected or day 0 were killed at the same time and analyzed similarly to infected mice.

\section{Pleural Cell and Fluid Preparation}

Thoracic cavities from naïve and infected mice were washed with $1 \mathrm{~mL}$ of $2 \mathrm{mmol} / \mathrm{L}$ EDTA-phosphate-buffered saline, samples were centrifuged, and supernatants containing pleural fluid were frozen at $-80^{\circ} \mathrm{C}$ for cytokine, chemokine, and $\mathrm{CFU}$ evaluation. Pleural cells were suspended in phosphate-buffered saline-1\% bovine serum albumin, counted, and used for cytospin, followed by May-GrünwaldGiemsa or Ziehl-Neelsen staining. For evaluation of monocytes/macrophages, lymphocytes, neutrophils, and infected cells, 400 to 500 cells were counted on cytospin and reported as percentage of total cell number in each pleural cell sample.

\section{Cytokine and Chemokine Flow Cytometry and Enzyme- Linked Immunosorbent Assay Analyses}

Cytokines and chemokines that have been shown to be activated by an i.v. BCG infection were analyzed in the pleural fluid and in the serum of naïve littermates, and at day 14 and 28 after infection. ${ }^{25}$ Interferon (IFN)- $\gamma$, IL-12p70, IL-6, TNF, IL10 , and monocyte chemotactic protein (MCP)-1 were quantified using a flow cytometry bead array assay (BD, San Jose, CA). Samples were acquired using a FACSCyan Cytometer and analyzed with FCAP Array software version 3.0. 
RANTES, MIP-1 $\alpha$, and keratinocyte-derived cytokine or CXCL1/KC were quantified by enzyme-linked immunosorbent assay (R\&D Systems, Abingdon, UK).

\section{Histologic Analysis}

Histologic analyses were performed in naïve and infected mouse tissues. Tissues were fixed in $4 \%$ phosphate-buffered formalin and paraffin embedded. Sections ( $5 \mu \mathrm{m}$ thick) were stained with hematoxylin and eosin or Ziehl-Neelsen. Histologic scores and free alveolar spaces were analyzed, as previously reported. ${ }^{27}$

\section{Immunohistochemistry}

Staining of paraffin-embedded, formaldehyde-fixed lung sections was evaluated for mesothelin expression. After deparaffinization, sections were incubated with anti-mouse mesothelin rabbit IgG affinity-purified antibody (C-ERC; Takara Bio Europe, France) for 90 minutes at room temperature. Second antibody, a goat anti-rabbit IgG horseradish peroxidase conjugate, was incubated for 30 minutes and detected with diaminobenzidine-peroxide substrate solution, and sections were counterstained with hematoxylin.

\section{Statistical Analysis}

Statistical analyses were performed with GraphPad Prism software version 6.01 (GraphPad Software, La Jolla, CA). $P<0.05$ was considered statistically significant. Experiments with two groups were analyzed with an unpaired Student's $t$ test, and experiments with more than two groups with one-way analysis of variance and nonparametric Kruskal-Wallis test.

\section{Results}

\section{Cell Accumulation in the Pleural Cavity after BCG Infection and Presence of Phagocytic Giant Cells}

BCG-induced pleural tuberculosis was generated by injecting $10^{6}$ CFUs BCG Pasteur strain into the pleural cavity. Previous studies have shown that BCG pleural infection induces an early neutrophil influx, followed by monocytes, and lymphocytes in the pleural cavity. ${ }^{22}$ To examine the importance of TNF, TNF receptors, and CCR5, deficient and wildtype (WT) control mice were infected, and the inflammatory cell recruitment into the pleural cavity at different time points after infection was determined and compared to those observed in naïve littermates. No differences between animal groups were observed in pleural cells from naïve mice. At day 14 after infection, there was a significant increase in the total number of cells (threefold to fivefold) in WT mice, which was more prominent in $\mathrm{TNF}^{-1-}$ and TNFR1R2 $2^{-1-}$ mice; these differences were maintained at day 28 after infection (Figure 1A). This increase concerned lymphocytes and monocytes/macrophages, which were higher in mice deficient for TNF or TNF receptors (Figure 1, B and C). Neutrophils were highly augmented in all infected mice without any difference between the groups (Figure 1D). At day 28 after infection, few cells were positively stained for mesothelin, a protein expressed by pleural mesothelial cells, indicating that at late infection, mesothelial cells can be found in the pleural cavity (Supplemental Figure S1A). Microscopic analysis of pleural cells showed that the most striking changes between groups were the presence of multinucleated giant macrophages (size, 30 to $50 \mu \mathrm{m}$ ), which were more frequently observed in the pleural cavity of $\mathrm{TNF}^{-/-}$and TNFR1R2 $^{-1-}$ mice (Figure 1, E-G). These giant macrophages contained numerous acid fast bacilli, as visualized by Ziehl-Neelsen staining, and vacuoles, suggesting a weakened killing activity in $\mathrm{TNF}^{-1-}$ and TNFR1R2 $2^{-/-}$mice compared to WT or CCR5 ${ }^{-1-}$ mice, which could normally kill BCG and avoid intracellular accumulation of vacuoles and bacilli (Figure 1, F and G). We addressed the question if inducible nitric oxide synthase (iNOS) expression was impaired in $\mathrm{TNF}^{-1-}$ and TNFR1R2 ${ }^{-/-}$macrophages and observed that iNOS was weakly immunostained in few macrophages of $\mathrm{TNF}^{-1-}$ and $\mathrm{TNFR}_{\mathrm{R} 2}{ }^{-1-}$ compared with WT pleural macrophages (Figure 1H). Thus, the absence of TNF pathway, but not of CCR5, induces an increased accumulation of infected giant macrophages in the pleural cavity, indicating that TNF may play a key role in allowing phagocytes to kill intracellular BCG by activating iNOS.

\section{BCG-Induced Pleurisy Activates the Release of Inflammatory Cytokines and Chemokines in the Pleural Cavity and in the Serum}

In view of the drastic inflammatory immune cell response, the accumulation of cytokines and chemokines mediating host reaction against mycobacteria was expected, as previously reported, using a different model of BCG infection. ${ }^{25}$ Indeed, IFN- $\gamma$ levels increased in the pleural cavity of BCG-infected WT mice, and increased even $>65$-fold more in $\mathrm{TNF}^{-1-}$ and TNFR $1 \mathrm{R}^{-1-}$ mice on day 14 and 28 after infection (Figure 2A). IL-12p70 levels increased in all gene-deficient mice at late infection as compared to WT mice (Figure 2B). By contrast, IL-6 levels in pleural fluid only increased in $\mathrm{TNF}^{-\prime-}$ and TNFR1R2 $2^{-1-}$ as compared to WT and $\mathrm{CCR}^{-1-}$ mice (Figure 2C). These data suggest exacerbated inflammation in the pleura of $\mathrm{TNF}^{-1-}$ and TNFR $1 \mathrm{R} 2^{-1-}$ mice associated with high activity of accumulated cells. TNF release was 25 -fold increased in TNFR1R2 ${ }^{-1-}$ mice, reaching 4 to $5 \mathrm{ng} / \mathrm{mL}$ at day 14 to 28 after infection (Figure 2D). The IL-10 level in the pleural cavity was increased twofold by day 28 after infection in $\mathrm{TNF}^{-1-}$ mice as compared to WT mice, but not in TNFR1R2 ${ }^{-l-}$ mice (Figure 2E). The differences between $\mathrm{TNF}^{-1-}$ and TNFR1R2 ${ }^{-1-}$ mice can be explained by the fact that homotrimeric LT $\alpha$, which plays a limited role in the presence of TNF during BCG infection, signals through TNF receptors. ${ }^{28}$ Both TNF $^{-1-}$ and TNFR1R2 ${ }^{-1-}$ mice had 
A

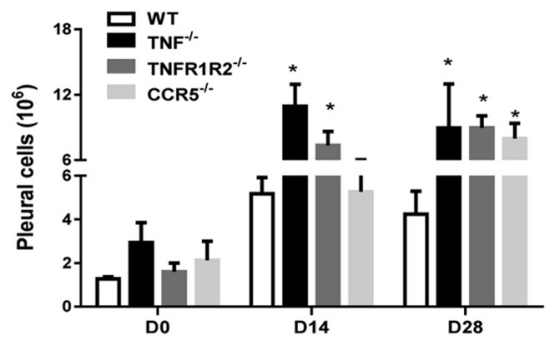

C

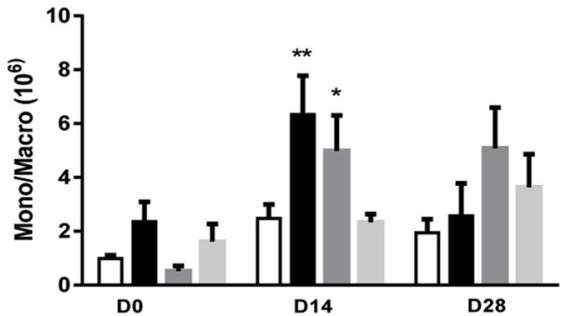

$\mathbf{E}$
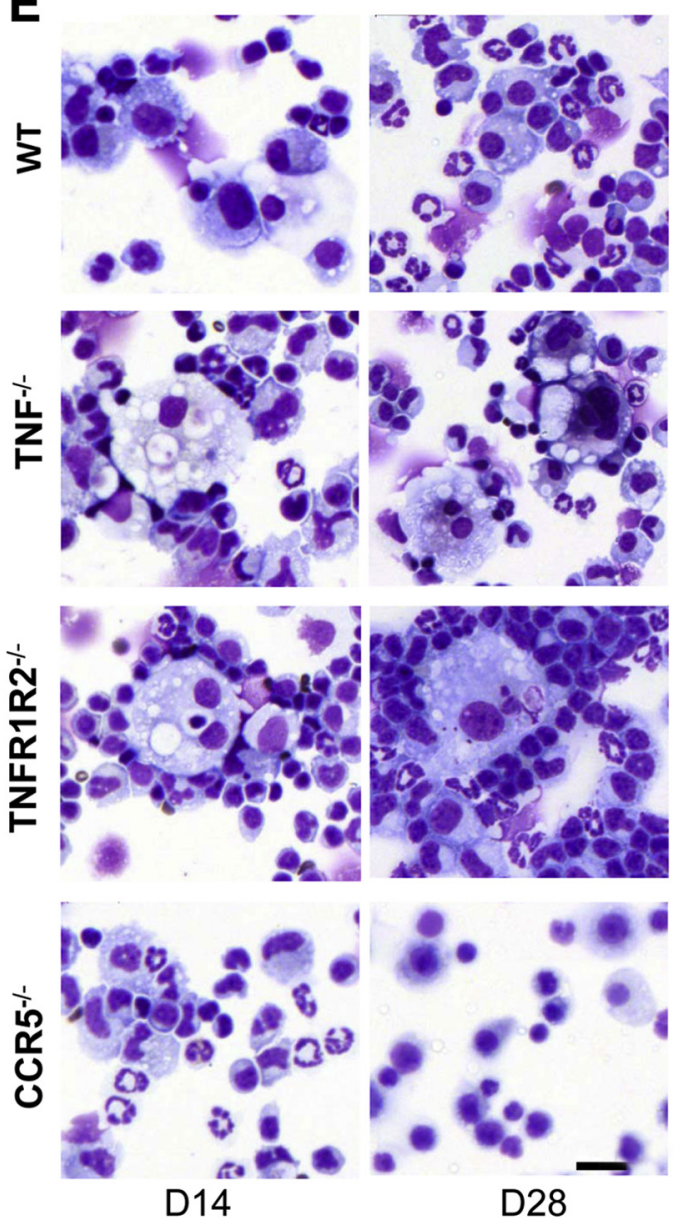

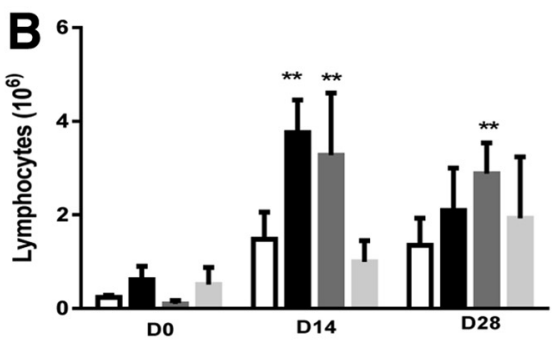

D

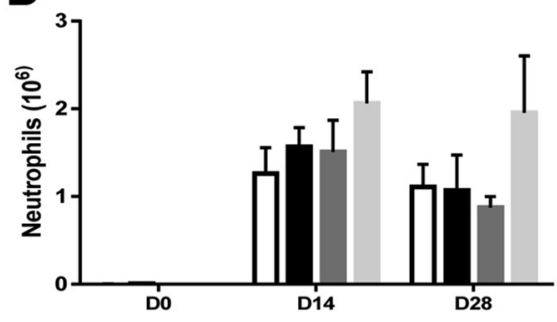

$\mathbf{F}$

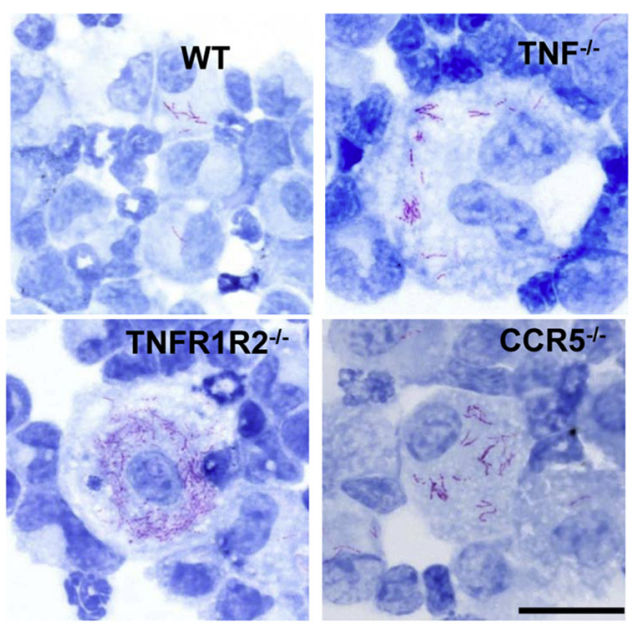

G

H
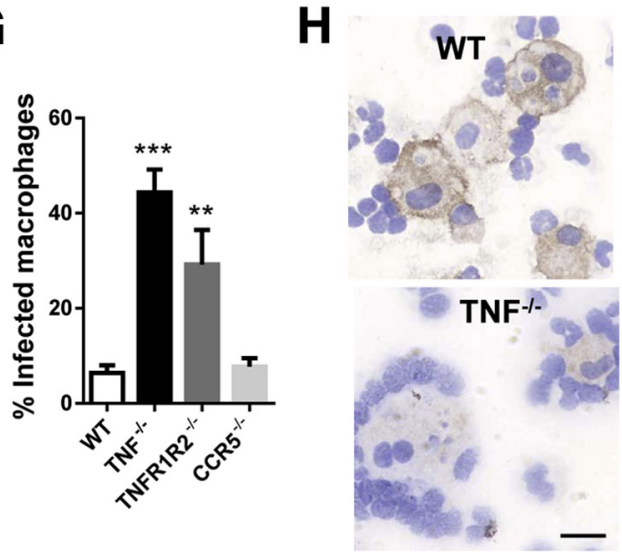

Figure 1 Bacillus Calmette-Guerin (BCG)-induced pleurisy and cellular accumulation of lymphoid and myeloid cells in the pleural cavity. A: Total number of cells from the pleural cavity in naïve littermates (D0) and at day 14 (D14) and 28 (D28) after BCG-induced pleurisy in WT, TNF ${ }^{-/-}$, TNFR1R2 ${ }^{-/-}$, and CCR5 ${ }^{-/-}$mice. Quantification of lymphocytes (B), monocytes/macrophages (Mono/Macro; C), and neutrophils (D) was performed on cytospin preparation stained with MayGrünwald-Giemsa. Total 400 to 500 cells were counted per sample and reported to total cell number per mouse. E: Photomicrographs from cytospin preparation with cells isolated from the pleural cavity at 14 and 28 days after BCG-induced pleurisy show macrophages, neutrophils, and lymphocytes. F: Ziehl-Neelsen staining of cytospin preparations with cells derived from day 14 after infection shows intracellular bacilli (red) in macrophages and in multinucleated giant cells. G: Bar graph represents the percentage of infected macrophages containing red bacilli at day 14 after infection counted on cytospin (total cell number 300 to 400 cells). H: Inducible NOS immunostaining on cytospin from 14 days infected mice. Experiments were repeated three times. Bar graphs show means \pm SEM (A-D and $\mathbf{G}) . n=6$ to 8 per group (H). ${ }^{*} P<0.05,{ }^{* *} P<0.01$, and ${ }^{* *} P<0.001$ versus WT. Scale bars $=20 \mu \mathrm{m}$. 
A

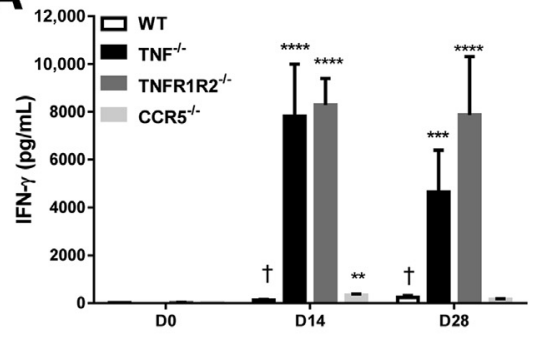

C

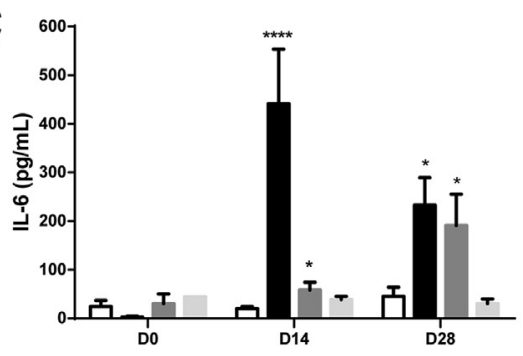

E

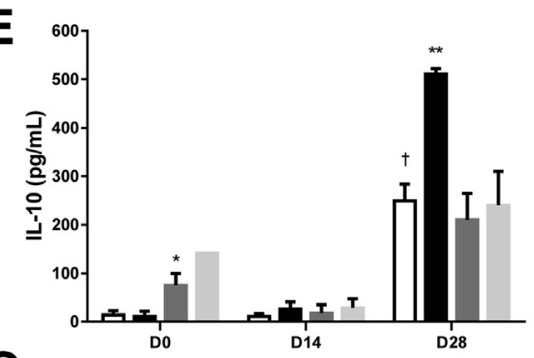

G

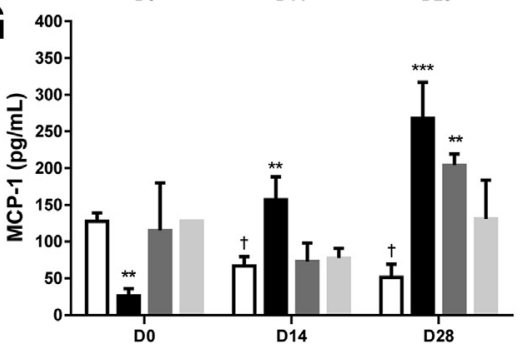

B

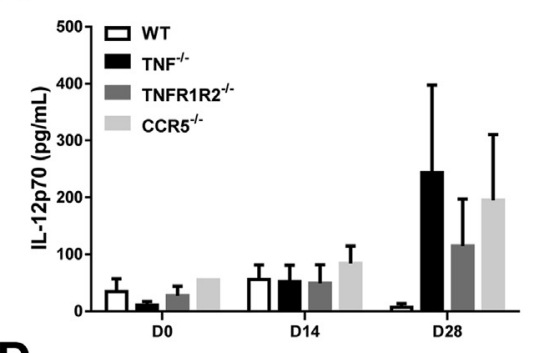

D

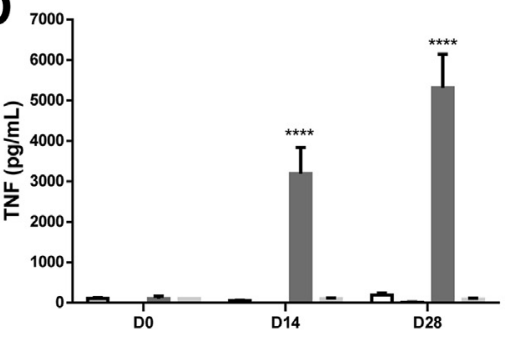

$\mathbf{F}$

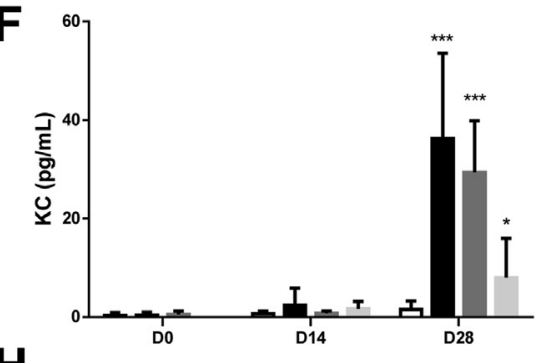

H

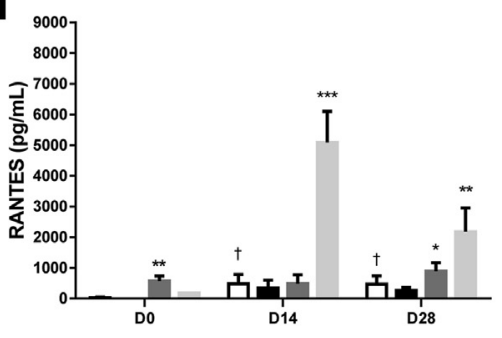

Figure 2 Bacillus Calmette-Guerin-induced pleurisy activates accumulation of high levels of cytokines and chemokines in WT, $\mathrm{TNF}^{-1}{ }^{-}$, TNFR1R2 $^{-1-}$, and $\mathrm{CCR}^{-/-}$mouse pleural fluid. A-H: Cytokine levels were assessed in the pleural fluid of naïve mice (D0) and at day 14 (D14) and 28 (D28) after infection. A: Interferon (IFN)- $\gamma$. B: IL-12p70. C: IL-6. D: TNF. E: IL-10. F: KC. G: Monocyte chemotactic protein (MCP)-1. H: Regulated on activation normal T cell expressed and secreted (RANTES). Bar graphs show means $\pm \operatorname{SEM}(\mathbf{A}-\mathbf{H}) . n=6$ per group $(\mathbf{A}-\mathbf{H})$. ${ }^{*} P<0.05,{ }^{* *} P<0.01,{ }^{* * *} P<0.001$, and $* * * * P<0.0001$ versus WT for the same time point; ${ }^{\dagger} P<0.05$ versus $D 0$ for the same animal group. higher CXCL1/KC and MCP-1 chemokines than WT mice (Figure 2, F and G). Two chemokines signaling through CCR5 were evaluated in the pleura, RANTES and MIP-1 $\alpha$. High levels of RANTES were found in $\mathrm{CCR} 5^{-1-}$ mice and $\mathrm{TNFR}_{1 \mathrm{R} 2}{ }^{-1-}$ but not in $\mathrm{TNF}^{-/-}$mice and WT mice (Figure $2 \mathrm{H}$ ). In contrast, MIP-1 $\alpha$ levels were increased by the infection but similar in all groups of mice (data not shown).

We further examined the levels of mediators in the serum of infected mice and observed that pleural BCG infection activated IFN- $\gamma$, but $\mathrm{TNF}^{-/-}$and TNFR1R2 $2^{-/-}$mice had higher levels of IFN- $\gamma$ than WT and $\mathrm{CCR}^{-/-}$mice (Figure 3A). IL-12p70 was augmented in the serum of infected mice, but levels were higher in $\mathrm{TNF}^{-1-}$ mice at day 14 after infection (Figure 3B). IL-6 was lightly released in the serum of all mice, but $\mathrm{CCR} 5^{-1-}$ mice showed low levels at day 28 after infection (Figure 3C). As previously observed in the pleural cavity, TNFR $1 \mathrm{R} 2^{-/-}$had high levels of TNF in serum (Figure 3D). $\mathrm{TNF}^{-1-}$ mice presented high levels of IL-10 in the serum unlike WT, TNFR1R2 ${ }^{-1-}$, or $\mathrm{CCR}^{-1-}$ mice (Figure 3E). MCP-1 was increased by the infection, but no difference between groups of mice was found (Figure 3F). Therefore, absence of TNF/TNFR1R2 pathway exacerbates the pleural proinflammatory environment, which is likely because of uncontrolled infection.

\section{BCG-Induced Pleurisy Modifies Visceral and Parietal Pleura and TNF Attenuates Tissue Changes}

The pleural cavity is covered by the visceral pleural mesothelium enveloping the lung parenchyma and the parietal pleura, which lines the inner chest and is composed of the mesothelium and a submesothelium fat layer. We examined both the visceral and the parietal pleura by microscopy to characterize the main pathology occurring in BCG-induced pleurisy. At day 14 after infection, all mice presented hyperplasia of the visceral pleura with increased thickness and no striking differences between the groups (Figure 4). At day 28 of infection, infected mutant mice displayed thick visceral pleura with enlargement of submesothelium at the site of inflammation. $\mathrm{TNF}^{-1-}$ and $\mathrm{TNFR} 1 \mathrm{R} 2^{-1-}$ mice and, 
A

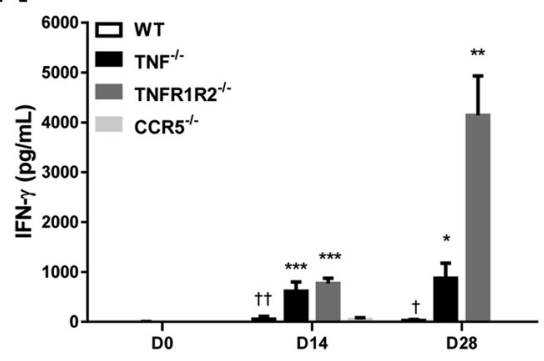

D

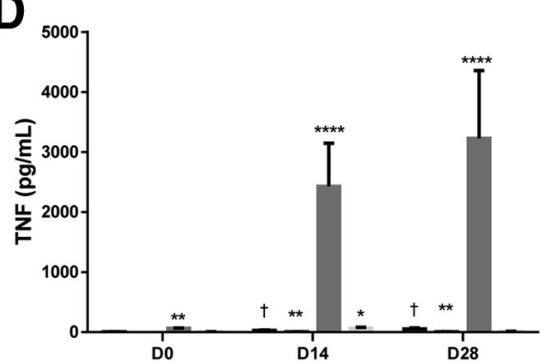

B

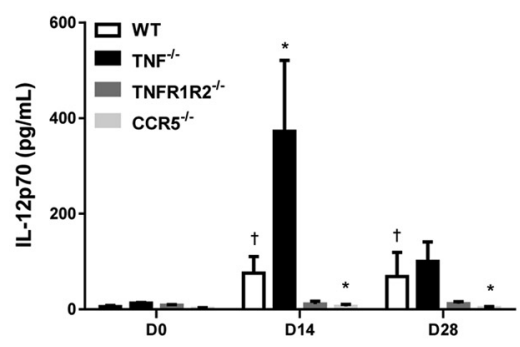

E

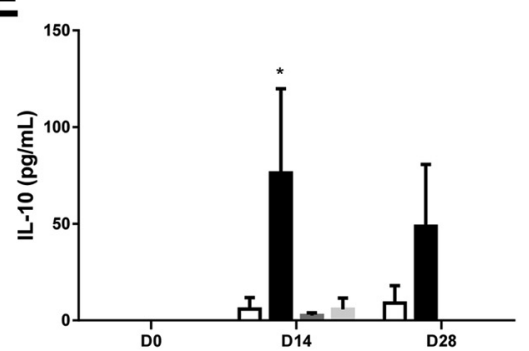

C

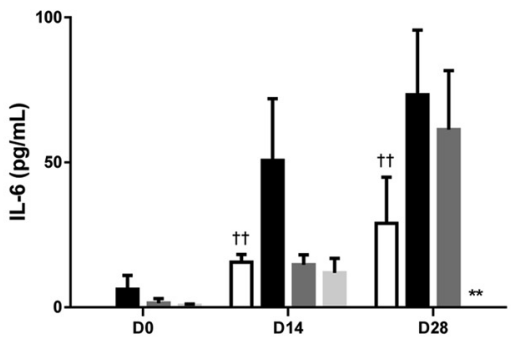

$\mathbf{F}$

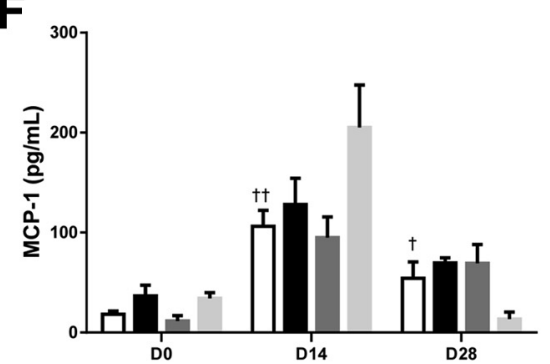

Figure 3 Bacillus Calmette-Guerin-induced pleurisy activates the release of cytokines and chemokines in the serum of WT, TNF ${ }^{-/}$, TNFR1R2 ${ }^{-/-}$, and CCR5 ${ }^{-/-}$ mice. A: Interferon (IFN)- $\gamma$. B: IL-12p70. C: IL-6. D: TNF. E: IL-10. F: Monocyte chemotactic protein (MCP)-1. Bar graphs show means \pm SEM (A-F). $n=6$ per group (A-F). ${ }^{*} P<0.05,{ }^{* *} P<0.01,{ }^{* * *} P<0.001$, and ${ }^{* * * *} P<0.0001$ versus WT for the same time point; ${ }^{\dagger} P<0.05,{ }^{\dagger \dagger} P<0.01$ versus naïve littermates (D0).

to a lesser extent, $\mathrm{CCR}^{-/-}$mice showed pulmonary lesions, including pleuritis, bronchiolitis, granuloma, pneumonia with increased pleural hyperplasia, decrease of free alveolar spaces, and higher pulmonary cell infiltration than WT mice (Figure 4, A and B). Immunostaining of mesothelin, a protein expressed by the mesothelium, evidenced alteration of the mesothelium barrier in mutant mice, and hyperplasia was observed in $\mathrm{TNF}^{-1-}$ and TNFR1R2 $2^{-1-}$ mice, but was less in $\mathrm{CCR}^{-1-}$ mice at day 14 after infection (Figure 5). At day 28 after infection, $\mathrm{TNF}^{-1-}$ and TNFR1R2 $2^{-1-}$ mice showed mesothelium hyperplasia and focal necrosis with discontinuity of the mesothelial barrier and occasional ulceration of the visceral pleural mesothelium (Figure 5 and Supplemental Figure S1, B and C). We then explored how the parietal pleural was modified by the BCG infection. At day 14 after infection, macroscopic examination evidenced the presence of several white foci resembling fat-like structures adherent to the dorsal part of the chest and diaphragm (Supplemental Figure S2A). White foci were more prominent in $\mathrm{TNF}^{-1-}$ and TNFR1R2 $2^{-l-}$ compared to WT and $\mathrm{CCR}^{-1-}$ mice (Figure 6A). Microscopic examination revealed that white nodules were formed by myeloid cells, lymphoid cells, and adipocytes (Figure 6B). The presence of BCG was identified by ZiehlNeelsen staining, and they were more abundant in $\mathrm{TNF}^{-1-}$ and TNFR1R2 $2^{--}$mouse tissues than in WT and CCR5 $5^{-1-}$ mice (Figure 6C). At day 28, white nodules were less frequent or absent in WT and CCR5 ${ }^{-1-}$ mice but abundant in $\mathrm{TNF}^{-1-}$ and TNFR1R2 ${ }^{-l-}$ mice. WT mice showed a predominance of adipocytes in the tissue, whereas $\mathrm{TNF}^{-/-}$and TNFR1R2 $2^{-1-}$ mice had fewer or absent adipocytes and enlarged regions of inflammatory cells (Figure 7A and Supplemental Figure S2B). Granulomas were observed in WT mouse white nodules that covered the parietal pleura, but only disorganized granulomatous structures and lymphocytic accumulation were observed in $\mathrm{TNF}^{-1-}$ and TNFR1R2 $2^{-1-}$ mice by day 28 after infection (Figure 7, A and B). WT mouse nodules exhibited few mycobacteria in macrophages located at the central part of a granuloma (Figure 7C). In contrast, $\mathrm{TNF}^{-1-}$ and $\mathrm{TNFR} 1 \mathrm{R} 2^{-/-}$mice showed no structured granulomas and mycobacteria were widespread in inflamed pleural submesothelium (Figure 7, B and C).

We next determined the bacterial load in the pleural fluid and observed that the amount of CFUs was relatively low in WT and CCR $5^{-1-}$ mice, indicating control of infection at 14 and 28 days after infection. As expected, mice deficient for TNF exhibited significant CFU increase $(>1 \log 10)$, but TNFR1R2 ${ }^{-1-}$ mice exhibited stronger bacterial loads $(>2$ $\log 10$ increase) in the pleural fluid on day 14 . Mice deficient for TNF or TNFR1R2 depicted significantly higher $(1 \log 10$ increase) bacterial loads than WT on day 28 after infection. However, $\mathrm{TNF}^{-1-}$ and TNFR1R2 ${ }^{-/-}$appeared to relatively control Bacillus proliferation as CFU in the pleural fluid was similar or lower at day 28 compared to day 14 after infection (Figure 7D). These results suggest substantial and early control of pleural BCG infection in $\mathrm{WT}$ and $\mathrm{CCR} 5^{-1-}$ mice but not in TNF or TNFR1R2 deficient mice.

\section{BCG-Induced Pleural Infection Leads to Systemic Disease in $\mathrm{TNF}^{-/-}$and TNFR1R2 ${ }^{-/-}$Mice}

We then analyzed whether a local infection in the pleura cavity may affect other organs and cause systemic inflammation. We evaluated relative organ weight as a surrogate 
A
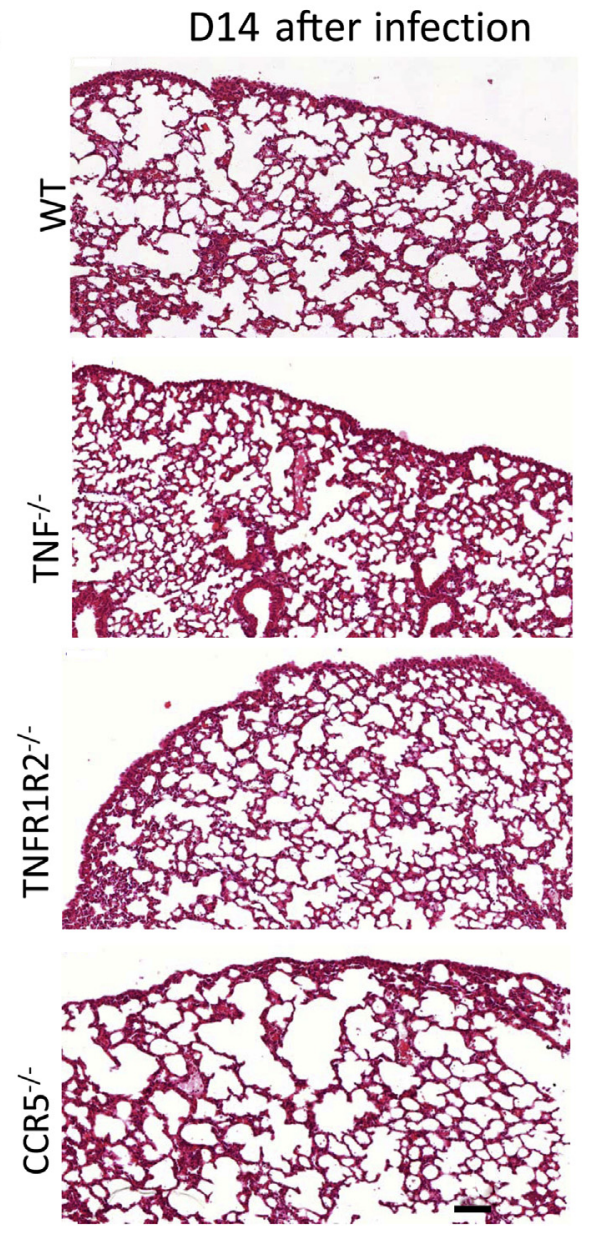

D28 after infection
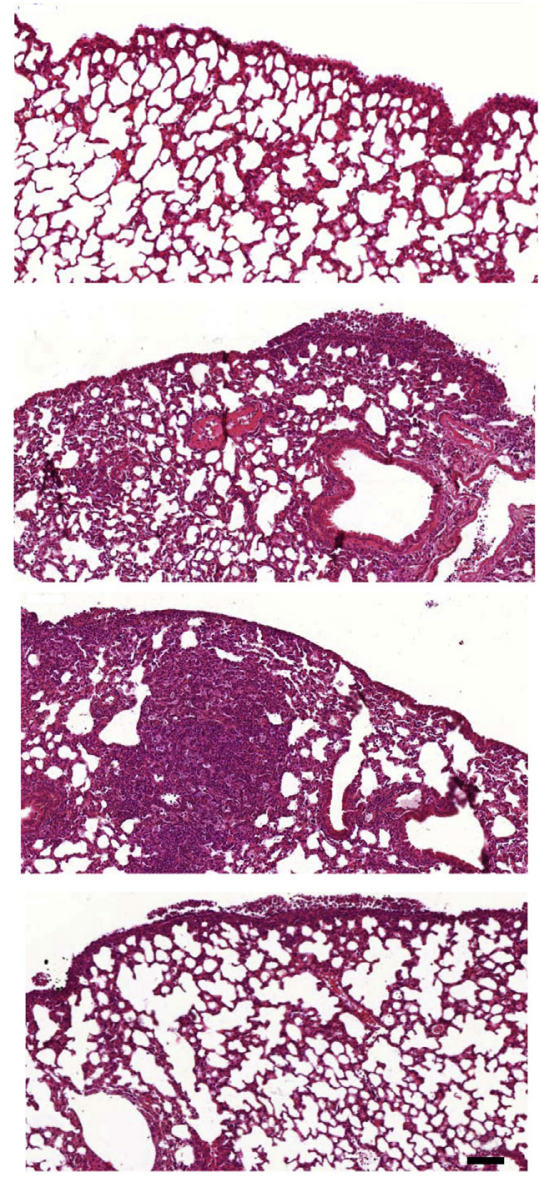

B

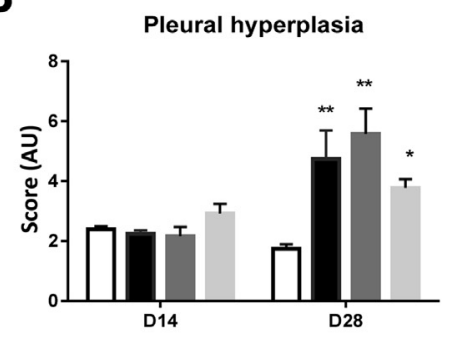

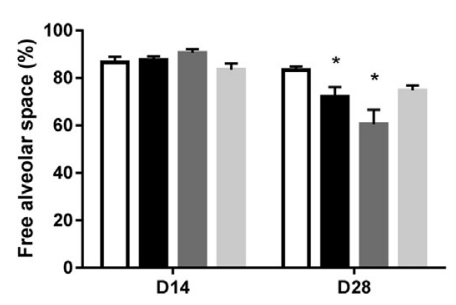

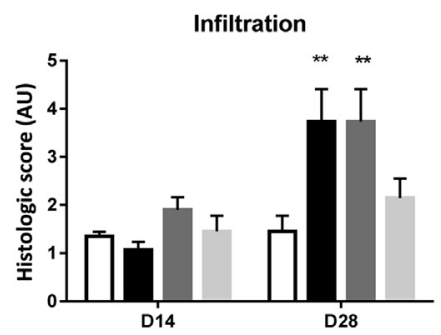

Figure 4 Bacillus Calmette-Guerin-induced pleurisy causes hyperplasia of the visceral pleura. A: Microscopic examination of lungs at day 14 and 28 after infection from WT, $\mathrm{TNF}^{-/}$, TNFR1R2 ${ }^{-/-}$, and $\mathrm{CCR}^{-/-}$mice (hematoxylin and eosin stain). B: Quantification of histologic pattern of visceral pleural hyperplasia, free alveolar space (\%), and scores of pulmonary infiltration. These results are representative of three to six mice per group. Bar graphs show means $\pm \operatorname{SEM}(\mathbf{B}) .{ }^{*} P<0.05,{ }^{*} P<0.01$ versus WT. Scale bars $=100 \mu \mathrm{m}(\mathbf{A})$. AU, arbitrary unit.

marker of organ inflammation. No changes in relative lung, liver, or spleen weights were observed between the groups of infected mice at day 14 after infection, but at day 28 $\mathrm{TNF}^{-1-}$ and TNFR1R2 ${ }^{-1-}$ mice showed a significant increase in lung, liver, and spleen relative weights compared to WT and $\mathrm{CCR}^{-1-}$ mice (Figure 8, A-C). This indicates that pleural BCG infection causes organ inflammation in $\mathrm{TNF}^{-1-}$ and TNFR1R2 ${ }^{-/-}$mice, suggesting disseminated BCG infection. Spleen bacterial loads correlated with relative spleen weight and showed that WT spleen contained few living bacilli; in contrast, spleens from $\mathrm{TNF}^{-1-}$ and TNFR1R2 ${ }^{-1-}$ mice contained high Bacillus count, leading to uncontrolled BCG infection and confirming disseminated BCG infection. In spleens from $\mathrm{CCR} 5^{-/}$, bacilli were not detected, indicating that these mice are able to totally control BCG infection (Figure 8D).

Microscopic examination of the liver showed granulomas at 28 days after infection. WT and CCR5 ${ }^{-1-}$ mice showed cellular infiltrations and small, rare lesions that were not well differentiated in contrast with $\mathrm{TNF}^{-1-}$ and TNFR1R $2^{-I-}$ mice, which had large and numerous liver granulomas (Figure 8, E and F). Survival studies showed BCG-induced pleurisy was fatal for $\mathrm{TNF}^{-1-}$ mice by 42 to 49 days and for TNFR $1 R 2^{-1-}$ mice by 35 to 42 days after infection (Figure 8G). Histopathological examination at necropsies of $\mathrm{TNF}^{-1-}$ and TNFR1R2 ${ }^{-1-}$ mice showed that liver exhibited extensive pathology, including numerous granulomas in the parenchyma, necrotizing granulomatous inflammation, hepatic capsulitis, or hepatoperitonitis, dilatation of sinusoids illustrating diminished liver perfusion and ischemia causing liver injury with atrophy of hepatocytes, and vasculitis of small and large vessels (Figure 9, $\mathrm{A}-\mathrm{E})$. The spleen of dying mice depicted numerous granulomas, endothelitis, and emboli (data not shown). The parietal pleura of $\mathrm{TNF}^{-1-}$ and TNFR1R2 $2^{-/-}$mice exhibited intercostal striated muscle fibers that underwent necrosis, which would cause respiratory distress in sick mice (Figure 9F). The lungs of $\mathrm{TNF}^{-1-}$ and TNFR1R2 ${ }^{-1-}$ exhibited pneumonia, arteritis, and granulomatous pleuritis with prominent accumulation of foamy macrophages (Figure 9, G and H). Macroscopically, both the visceral and parietal pleura depicted numerous abscesses, appearing as 


\section{A}

\section{Uninfected}

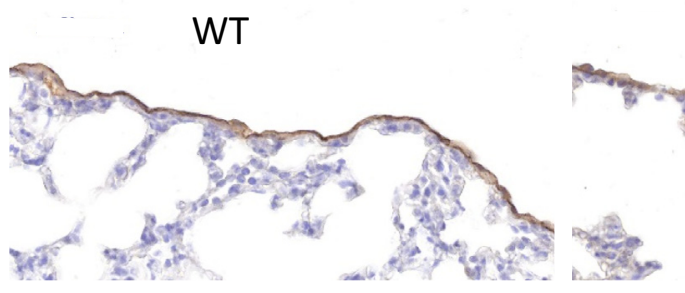

\section{$\mathrm{TNF}^{-/-}$}

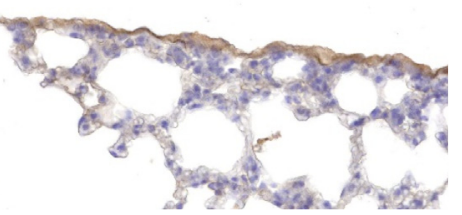

TNFR1R2-/-

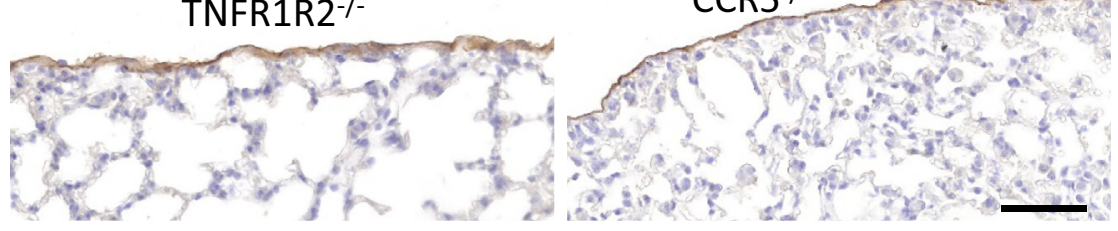

B

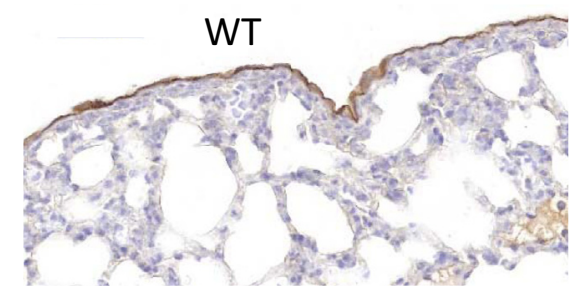

Day 14 afterinfection

TNFR1R2 ${ }^{-/-}$

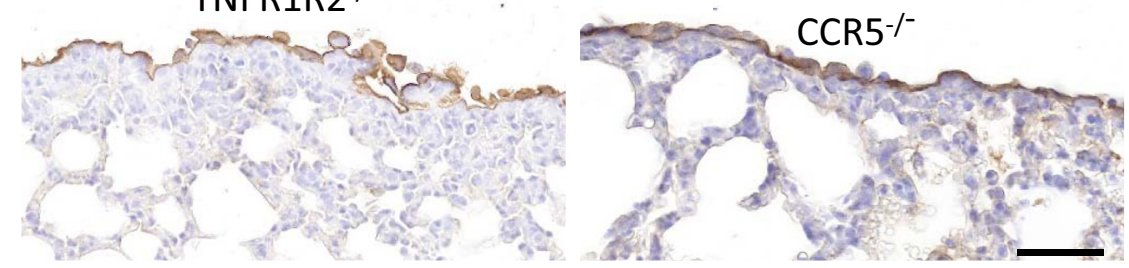

C

Day 28 afterinfection
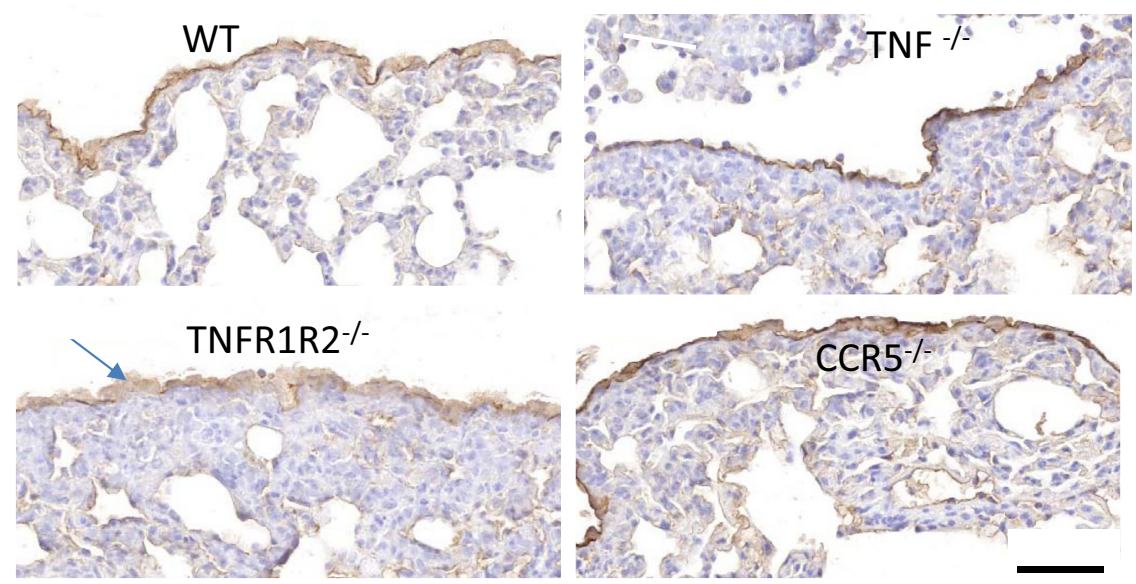

Figure 5 Mesothelin immunostaining in naïve littermates (uninfected) and infected mice. Visceral pleural mesothelium is altered by bacillus CalmetteGuerin (BCG) infection. Lung immunostaining of mesothelin detecting the mesothelial cells in uninfected or naïve littermates and after 14 and 28 days of BCG pleural infection. A: No differences are found in uninfected WT, TNF ${ }^{-/}$, TNFR1R2 ${ }^{-/-}$, and $\mathrm{CCR}^{-/-}$mice. B: At day 14 after infection, mice show thickening of the visceral pleura. $\mathrm{TNF}^{-/-}$and TNFR1R2 ${ }^{-/-}$mice show mesothelium hyperplasia and discontinuity of the barrier. C: At day 28 after infection, hyperplasia of the visceral pleural is exhibited in $\mathrm{TNF}^{-/}$and TNFR1R2 ${ }^{-/-}$mice, which also show eventual necrosis of the mesothelium (arrow). Images are representative of three mice per group. Scale bars $=50 \mu \mathrm{m}$. white nodules, and regions of adhesion between visceral and parietal pleural (synechia). This pathology was associated with presence of acid fast bacilli in examined organs, which reflected a miliary tuberculosis with general organ dysfunction in $\mathrm{TNF}^{-/-}$and TNFR1R2 $2^{-/-}$but not in WT and $\mathrm{CCR}^{-/-}$mice, which controlled the infection.

\section{Discussion}

The present study analyzes the role of TNF, TNF receptors, and CCR5 in murine BCG-induced pleurisy and shows that TNF pathway is required for host protection in contrast to CCR5, which is dispensable for infection control. Absence of 


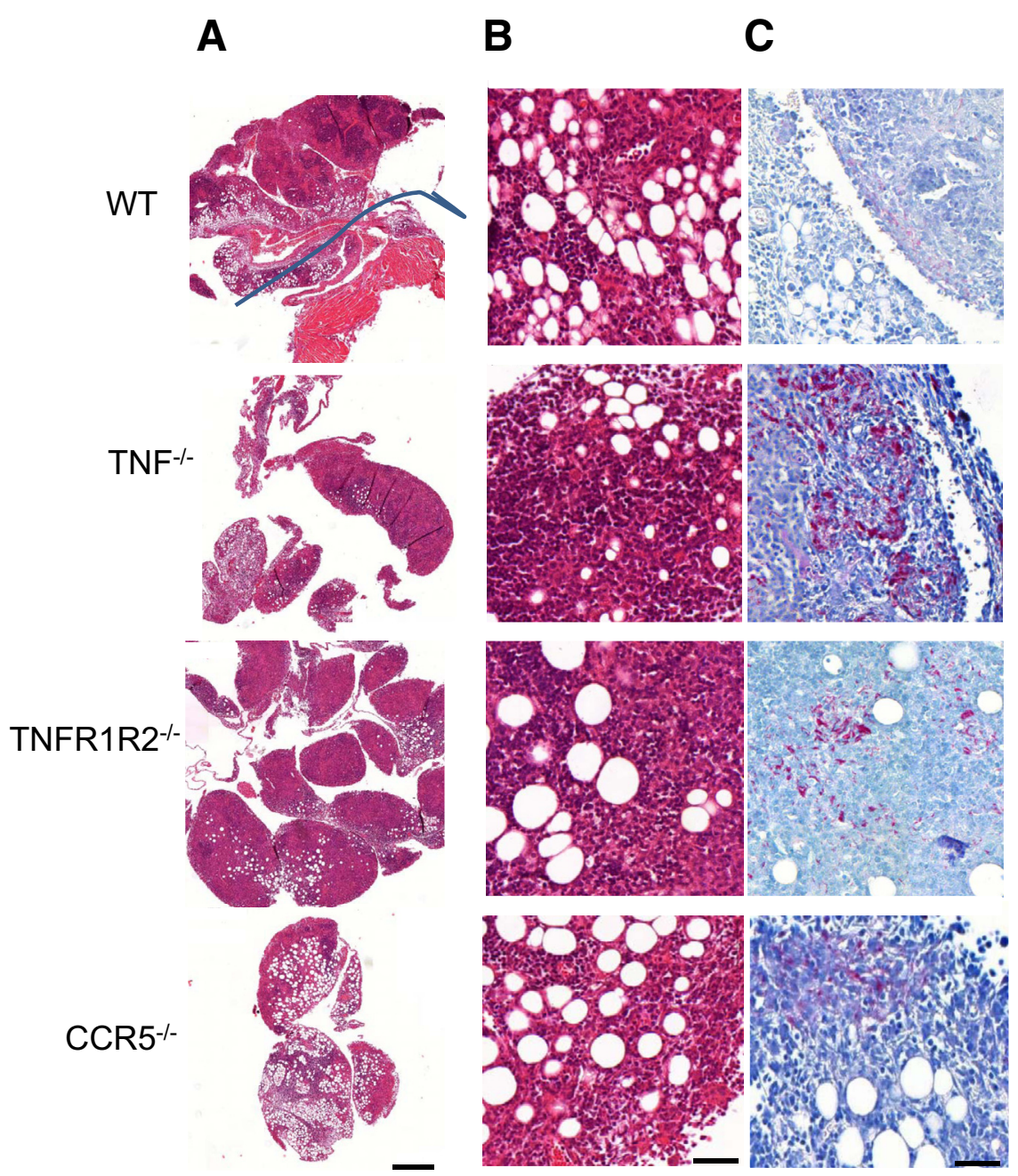

Figure 6 BCG-induced pleurisy results in alteration of the parietal pleural mesothelium in WT, $\mathrm{TNF}^{-1-}$, TNFR1R2 ${ }^{-/-}$, and $\mathrm{CCR}^{-/-}$mice at day 14 (D14) after infection. A and B: Hematoxylin and eosin staining of one of the white foci (size, 1 up to $6 \mathrm{~mm}$ ) from the chest of infected mice appearing as polypoid nodules and containing thickened parietal pleural mesothelium and submesothelial fat layer colonized by myeloid and lymphoid cells. In the WT parietal pleura, continuation of the pleural mesothelium and muscle tissues is observed; a blue line separates striated muscle cells from parietal mesothelium structures. C: Ziehl-Neelsen staining shows BCG as red patches in $\mathrm{TNF}^{-/-}$and TNFR1R2 ${ }^{-1-}$ and less abundance in $\mathrm{CCR}^{-1-}$ tissues. $n=6$ to 8 mice per group. Scale bars: $500 \mu \mathrm{m}(\mathbf{A}) ; 50 \mu \mathrm{m}($ B) $; 10$ $\mu \mathrm{m}(\mathbf{C})$.

\section{D14 after infection}

TNF or TNF receptor signaling during BCG-induced pleurisy resulted in systemic inflammation and infection, with generation of granulomas becoming necrotizing granulomatous inflammation in the liver and uncontrolled bacterial growth in the spleen. Pleural infection caused recruitment and accumulation of inflammatory cells, including neutrophils, macrophages, and lymphocytes inside the pleural cavity, as reported in other animal studies ${ }^{19,21,22,29}$ and in human pleuritis caused by M. tuberculosis infection. ${ }^{30}$ It has been reported that anti-TNF antibody administrated at early stages of BCG-induced pleurisy prevented the early (24 hours) neutrophil influx, which may indicate that TNF plays a role on the accumulation of neutrophils into the pleural cavity. ${ }^{21}$ Herein, we show that lack of TNF/TNFR1R2 pathway does not prevent neutrophil accumulation inside the pleural space at 2 to 4 weeks after $M$. bovis BCG infection. These new results are not in contradiction with previous ones with antiTNF antibodies, which may act by cell depletion, as TNF can have many different activities dependent on kinetics of the infection and apparently can enhance neutrophil accumulation at the early infection. ${ }^{21}$

We have examined BCG-induced pleurisy cell recruitment and observed that the numbers of monocytes, macrophages, and infected phagocytes in the pleural effusion were considerably increased in the absence of TNF or TNF receptors. Phagocytes from mutant TNF or TNF receptors contained numerous acid fast bacilli, suggesting that they failed to eliminate bacilli that would proliferate intracellularly. We have previously reported that $\mathrm{TNF}^{-/-}$and TNFR1R2 ${ }^{-l-}$ were highly sensitive to an i.v. BCG infection. TNF or TNFR1R2 mutant mice died after 30 to 40 days infection because of bacterial overgrowth and impaired activation of iNOS in infected organs. ${ }^{25}$ Host protection against BCG involves activation of the iNOS-dependent bactericidal mechanisms as mice deficient in iNOS were shown to be unable to develop cell-mediated immune responses and died from BCG infection. ${ }^{31}$ Pleural macrophages from $\mathrm{TNF}^{-\prime-}$ and TNFR1R2 $2^{-I-}$ mice exhibited 


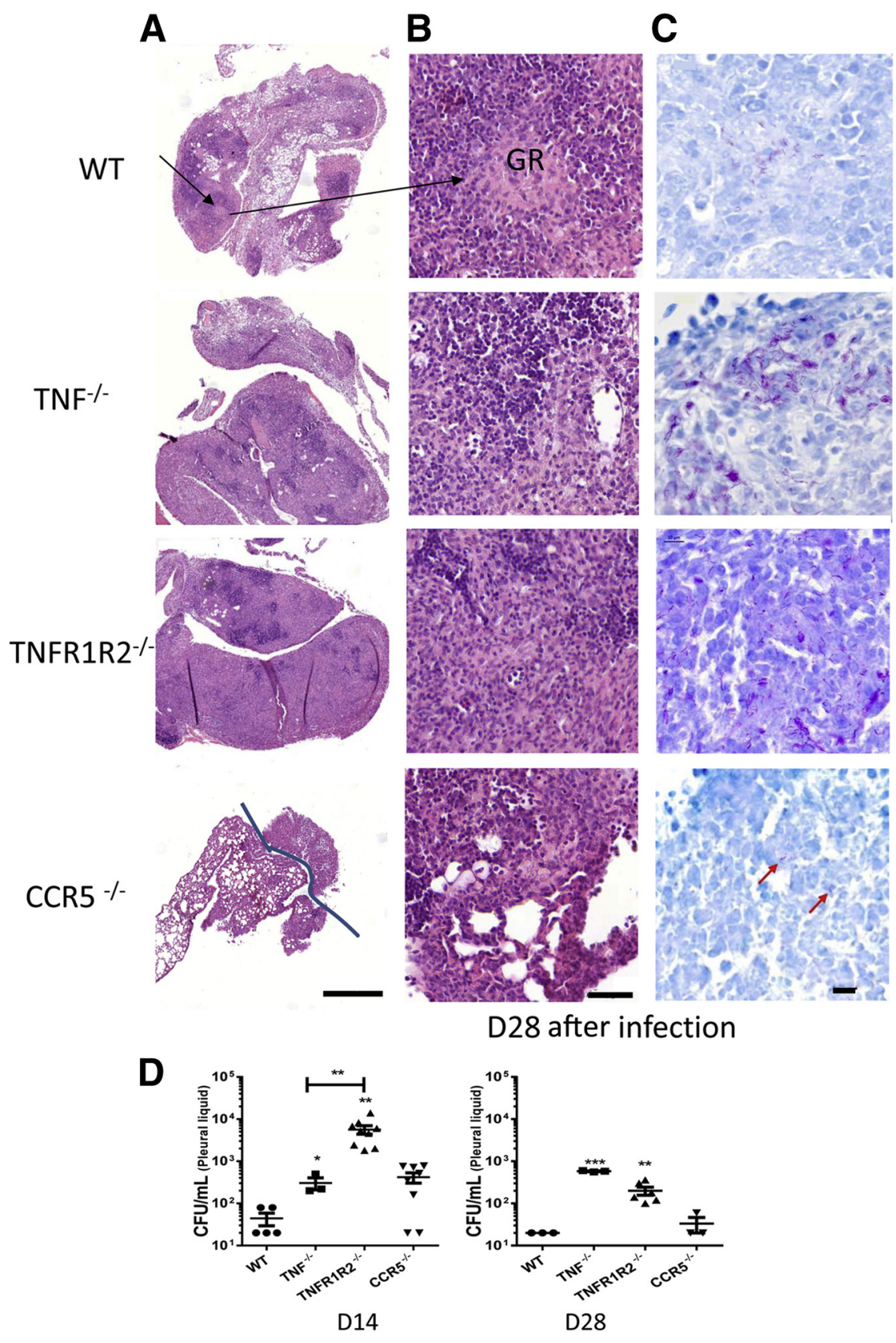

Figure 7 Bacillus Calmette-Guerin-induced pleurisy results in alteration of the parietal pleura mesothelium and fat layer at day 28 after infection. A: Nodules are rare in WT, but they can contain granulomatous structures. $\mathrm{TNF}^{-/-}$and TNFR1R2 ${ }^{-/-}$ mice present abundant parietal pleural white nodules showing disorganized cellular structures. CCR5 ${ }^{-/-}$ mice exhibit few parietal nodules and visceral mesothelial adherences to the parietal mesothelium; a blue line delimitates lung tissue from mesothelium at the adherence points. B: Granuloma structures are indicated by arrow in WT mouse tissue; in contrast, in $\mathrm{TNF}^{-/-}$and TNFR1R2 ${ }^{-/}$nodules do not show granuloma but structures appear disorganized. C: Ziehl-Neelsen staining shows weak bacilli staining (red) in WT macrophages of central part of a BCG granuloma, but $\mathrm{TNF}^{-1-}$ and TNFR1R2 ${ }^{-/-}$tissues present numerous red bacilli. Bacilli are rare in $\mathrm{CCR}^{-/-}$mice (arrows). D: Bacterial load in the pleural fluid of BCG-infected mice. Colony-forming units (CFUs) were assessed in the pleural fluid of WT, $\mathrm{TNF}^{-/-}$, TNFR1R2 ${ }^{-1-}$, and $\mathrm{CCR}^{-/-}$mice at day 14 (D14) and 28 (D28) after infection. Graphs show means \pm SEM (D). $n=6$ to 8 mice per group (A-C); $n=4$ to 6 mice per group (D). ${ }^{*} P<0.05$, ${ }^{* * P}<0.01$, and ${ }^{* * *} P<0.001$ versus WT. Scale bars: $500 \mu \mathrm{m}($ A) $; 50 \mu \mathrm{m}$ (B); $10 \mu \mathrm{m}$ (C). GR, central part of the granuloma in WT.

deficient iNOS compared to WT macrophages, suggesting that mice deficient for TNF or its receptors are not able to efficiently develop bactericidal mechanisms to fight BCG pleural infection, leading to uncontrolled infection.

Absence of TNF also affected the accumulation of lymphocytes after BCG infection. TNF has been identified as a negative regulator of $\mathrm{T}$ helper 1-type immune responses during mycobacterial infection, resulting in uncontrolled expansion of CD4 T cells producing IFN $-\gamma^{32}$ At 2 weeks after infection, lymphocyte count was higher in $\mathrm{TNF}^{-/-}$and $\mathrm{TNFR}_{\mathrm{R}} 2^{-1-}$ mice than in WT and CCR5 ${ }^{-1-}$ mice, indicating that TNF regulates also the accumulation of lymphocytes during BCG-induced pleurisy, probably by mechanisms involving NO. ${ }^{33,34}$ Previous studies have shown that BCG-induced pleurisy resulted in two waves of $\mathrm{T}$ lymphocyte accumulation, one at early infection, which is dependent on T-cell migration, and a second, at 15 days after infection, which appears to depend on local T-cell proliferation mediated by cytokines released in situ. ${ }^{23}$

We have examined the cytokines accumulated in the pleural space during the infection and found that $\mathrm{TNF}^{-/-}$ and TNFR1R2 $2^{-1-}$ mice have high levels of IFN- $\gamma$ throughout the infection. The presence of IFN- $\gamma$ has been associated with multinucleated giant cell formation in vitro and IFN- $\gamma$ inhibition blocked cytokine-induced generation of multinucleated giant cells. ${ }^{35}$ Exacerbated IFN- $\gamma$ levels in the pleural fluid of $\mathrm{TNF}^{-1-}$ and TNFR1R2 $2^{-1-}$ mice could be associated with the high number of multinucleated giant 
A

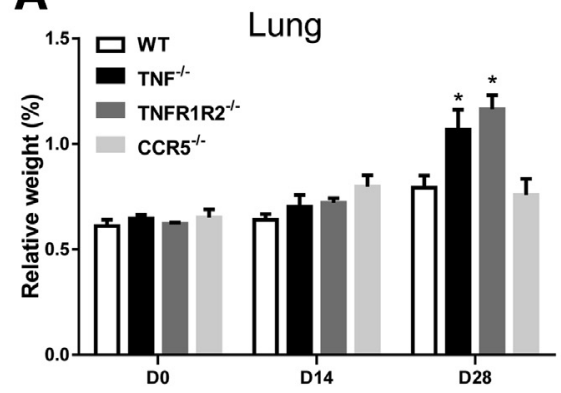

C

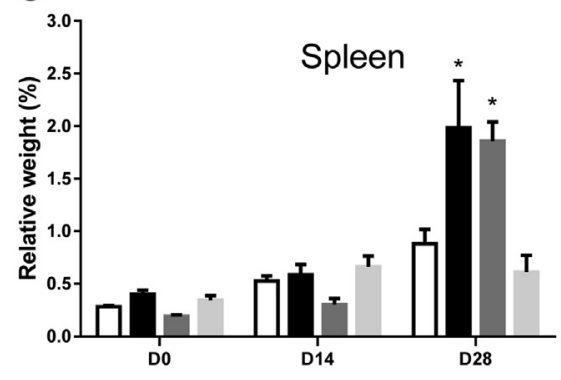

E

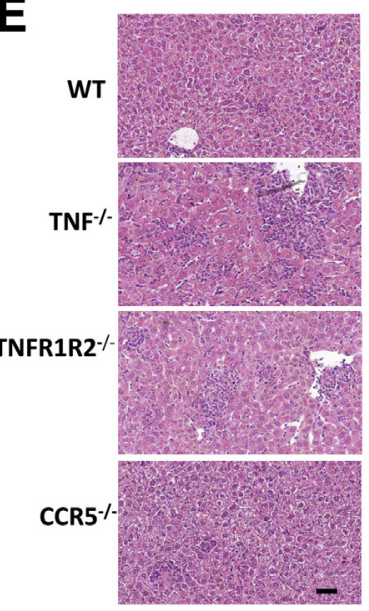

$\mathbf{F}$
B

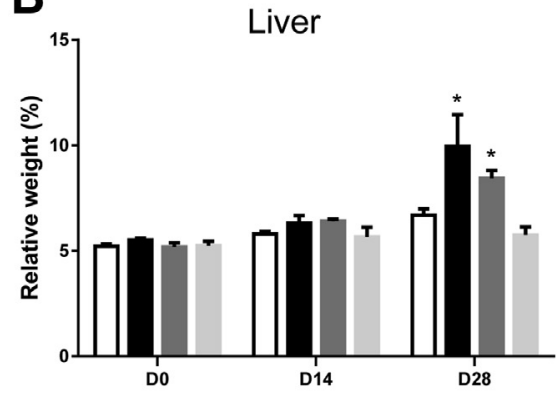

D
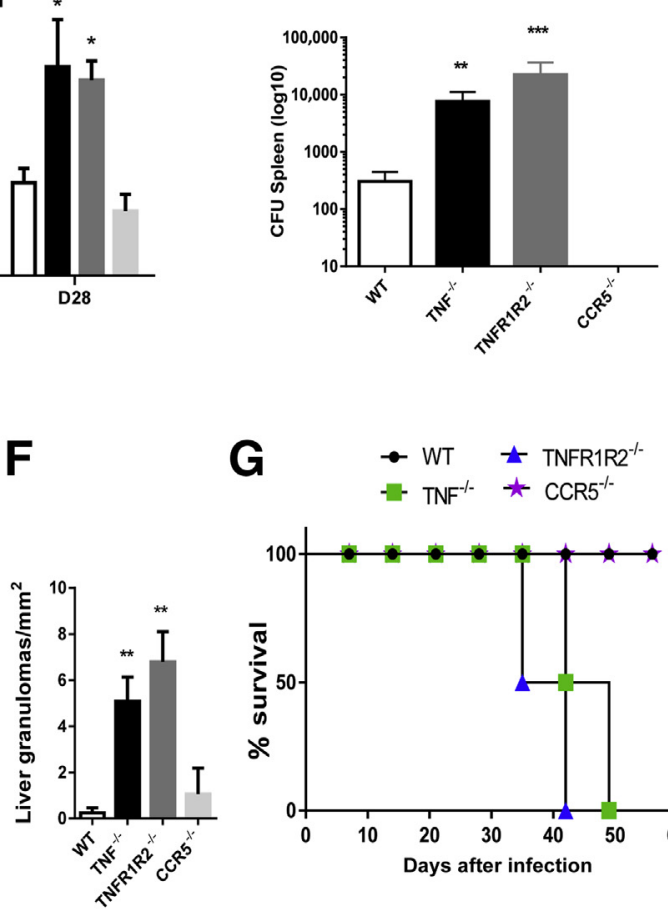

G

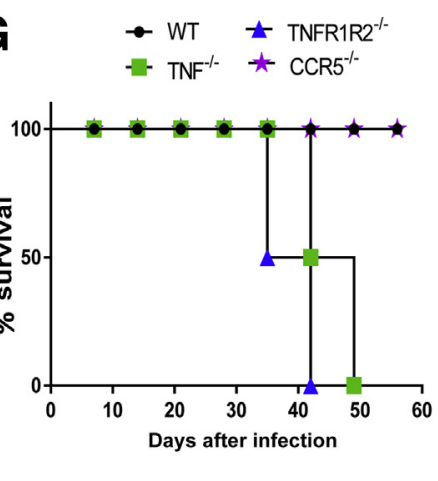

Figure 8 Pleural bacillus Calmette-Guerin (BCG) infection leads to systemic and fatal infection in $\mathrm{TNF}^{-/}$and TNFR1R2 ${ }^{-1-}$ mice. Relative organ weight in naïve littermates (D0) and at day 14 (D14) and 28 (D28) after infection for the lung (A), liver (B), and spleen (C). D: Bacterial load in the spleen of WT, $\mathrm{TNF}^{-/-}$, TNFR1R2 ${ }^{-/-}$, and $\mathrm{CCR}^{-1-}$ mice at day 28 after infection. E: Microscopic examination of liver from mice at day 28 after infection (hematoxylin and eosin stain). F: Quantification of liver granulomas at day 28 after infection. G: Survival curve of BCG-infected mice and fatal infection for $\mathrm{TNF}^{-/-}$and TNFR1R2 ${ }^{-/-}$ mice. Results are representative of two experiments. Bar graphs show means $\pm \operatorname{SEM}(\mathbf{A}-\mathbf{D}, \mathbf{F})$. $n=3$ to 6 mice per group $(\mathbf{A}-\mathbf{G}) .{ }^{*} P<0.05$, $* * P<0.01$, and $* * * P<0.001$ versus WT. Scale bar $=50 \mu \mathrm{m}$ cells. IL-6 was also increased in pleural fluid of $\mathrm{TNF}^{-1-}$ and TNFR1R2 ${ }^{-1-}$ mice but not in WT mice. In contrast, IL-10 responses in pleural fluid and serum were only observed in $\mathrm{TNF}^{-1-}$ mice, indicating that TNF, but not TNFR1R2, is regulating IL-10, which merits further investigation on the regulatory mechanisms. A schematic representation of the cytokine/chemokine network induced by BCG infection and TNF activation is illustrated in Supplemental Figure S3. Two cytokines closely related to TNF also induced by BCG but mainly produced by lymphocytes are the homotrimeric LT $\alpha$, which interacts with TNFR1 and TNFR2, and the heterotrimeric LT $\alpha 2 \beta 1$, which binds to a different receptor. ${ }^{36,37}$ Indeed, $\mathrm{TNF}^{-1-}$ and TNFR1R2 ${ }^{-1-}$ mice depicted a distinct pattern of inflammatory cytokines after BCG infection, suggesting that LT $\alpha$ may account for these differences observed in the pleural fluid and in the serum. LT $\alpha$ was shown to be dispensable for the control of i.v. BCG infection using neo-free $\mathrm{LT} \alpha^{-1-}$ mice with unperturbed
TNF expression; however, LT $\alpha$ signaling through TNF receptors may contribute to control chronic infection. ${ }^{28}$ TNFR1 was shown to be the predominant receptor mediating host protection against mycobacterial infection, whereas TNFR2, through the soluble sTNFR2 form neutralizing TNF, was shown to play a detrimental role during the infection. ${ }^{38,39}$ However, transmembrane TNF in the absence of soluble TNF and LT $\alpha$ was able to mediate protective immunity against both BCG and acute $M$. tuberculosis infection. ${ }^{40}$ The complex interplay between TNF and TNF receptors, either membrane bound or soluble, or with other molecules may result in the observed differences between the absence of TNF or the absence of TNFR1 and TNFR2.

The cytokine and chemokine content of the pleural fluid reflects a proinflammatory environment that favors cell recruitment as well as in situ cell proliferation. ${ }^{41}$ Consequently, the pleural mesothelium, which is highly reactive to 
A

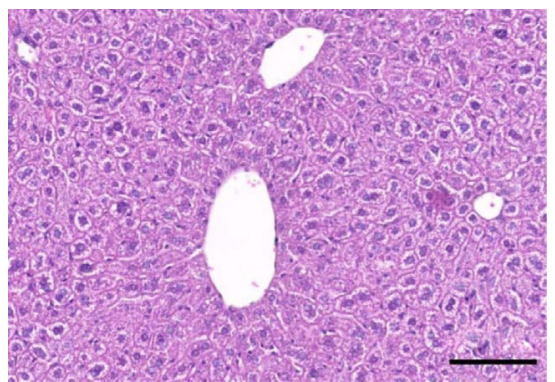

C

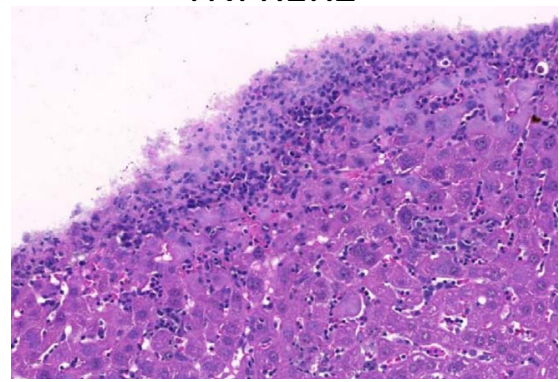

E

TNFR1R2 $\%$

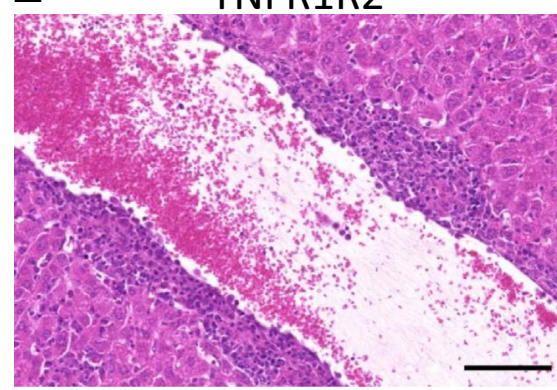

G

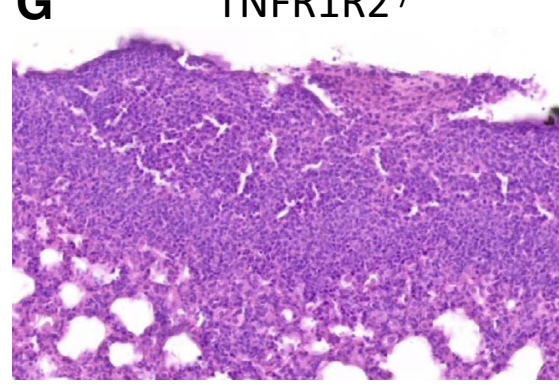

B

\section{$\mathrm{CCR} \%$}

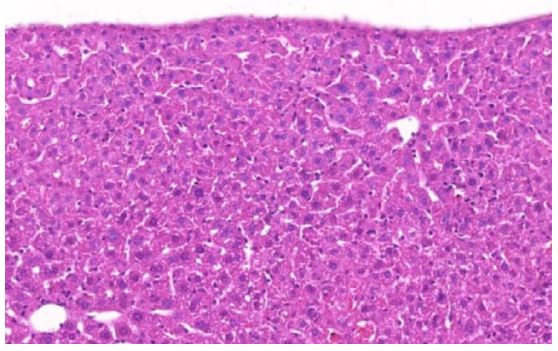

D

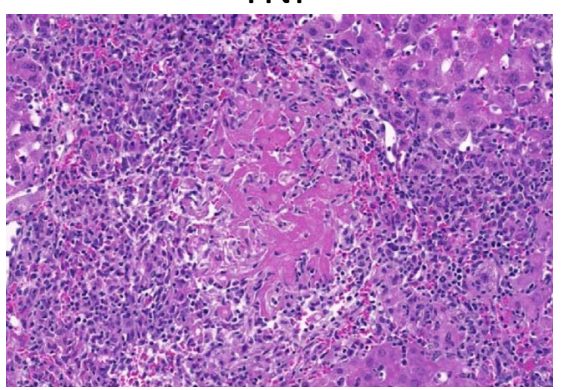

$\mathbf{F}$

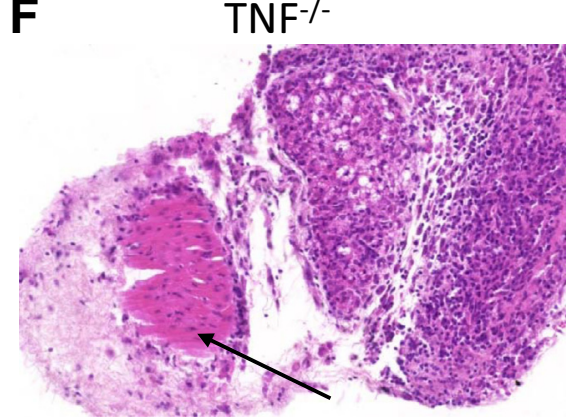

H TNF $^{-/}$

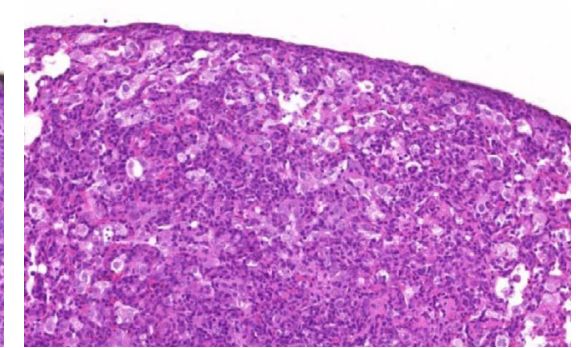

Figure 9 Fatal bacillus Calmette-Guerininduced pleurisy leads to uncontrolled infection in the absence of TNF or TNF receptors. Histopathological examination of liver and lung tissues from WT and $\mathrm{CCR}^{-/-}$infected mice at day 50 after infection or at necropsy from $\mathrm{TNF}^{-/-}$and TNFR1R2 ${ }^{-/-}$mice. A: Liver histology from WT mouse at day 50 after infection. B: Liver histology from $\mathrm{CCR}^{-/-}$mouse at day 50 after infection. C: Histology from TNFR1R2 ${ }^{-/-}$ mouse exhibiting liver capsulitis and dilatation of sinusoids. D: Liver histology showing necrotizing hepatic granuloma in the liver of a $\mathrm{TNF}^{-/-}$mouse. E: Histology from TNFR1R2 ${ }^{-/-}$mice exhibiting granulomatous vasculitis. F: Parietal pleura histology from $\mathrm{TNF}^{-/-}$mouse showing intercostal striated muscle with inflammatory infiltration affecting muscle fibers, which appear necrotic (arrow). G: Histology of lung from TNFR1R2 ${ }^{-/}$mouse exhibiting thickness of the visceral pleura, which could form synechia or adhesion with the parietal pleura. $\mathrm{H}$ : Lung histology from $\mathrm{TNF}^{-1-}$ mouse showing a subpleural granulomatous structure containing numerous foamy macrophages. $n=5$ to 6 mice per group. Scale bars $=$ $100 \mu \mathrm{m}(\mathbf{A}-\mathbf{H})$. bacteria, responds by proliferation and undergoes hyperplasia, resulting in thicker visceral and parietal pleura layers, as observed mainly in $\mathrm{TNF}^{-1-}$ and TNFR1R2 $2^{-1-}$ mice. Our results show that the pathology observed in $\mathrm{TNF}^{-1-}$ mice was associated with higher levels of KC and MCP-1, specifically in the pleural fluid cavity, but not in serum, suggesting that mesothelial cells could contribute to produce these chemokines. Mesothelial cells could be detected in the BCG-induced pleural effusions, probably contributing to the cytokine and chemokine pleural content. In vitro, stimulation with BCG of mouse mesothelial pleural cells induced chemokine and cytokine expression, which could also influence the recruitment of mononuclear cells to the pleural cavity. ${ }^{42,43}$ BCG increased the permeability of mesothelial cells by altering mesothelial junction molecules. ${ }^{44} \mathrm{We}$ observed that macroscopically the parietal pleura presents lesions reminiscent of early stages of mesothelioma with focal adhesion and multiple polypoid nodules or white foci, ${ }^{45}$ colonized by bacilli mainly in $\mathrm{TNF}^{-1-}$ and TNFR1R2 ${ }^{-/-}$mice, which may represent niches for mycobacteria inside the parietal pleural mesothelium. These lesions appeared to resolve in WT and CCR5 $5^{-1-}$ mice but not in $\mathrm{TNF}^{-/-}$and TNFR1R2 ${ }^{-/-}$mice, and were associated with persistence of living bacilli inside the pleural space and in the spleen. Indeed, as $\mathrm{TNF}^{-1-}$ and TNFR $1 \mathrm{R} 2^{-1-}$ mice were unable to eliminate $\mathrm{BCG}$, they could not repair the 
injured pleura and resolution failed with fatal consequences in these mice because of disseminated BCG infection.

Pleural mesothelial cells are phagocytic cells that can migrate into the lung parenchyma and differentiate into subpopulations, including myofibroblasts. ${ }^{46}$ Granulomatous lesions are observed in the lung parenchyma during advanced infection. This secondary infection results from lymphatic and blood circulation bacteria, or it can be speculated that infected pleural mesothelial cells migrate to the pulmonary parenchyma.

Pleural $\mathrm{TB}$ is an extrapulmonary $\mathrm{TB}$ found in patients with or without pulmonary TB. A recent study has reported that among the sites of concurrent extrapulmonary TB, the pleura was the most frequently infected site. ${ }^{47}$ An increase in extrapulmonary TB has been reported by several studies, including one showing that extrapulmonary TB increased in the United Kingdom from $48 \%$ in 1999 to $53 \%$ in 2006 . $^{14}$ However, studies provide different frequencies dependent on geographic situation and subjects affected by the disease and many factors that are not fully identified.

TNF neutralization has provided efficient treatments for several severe autoimmune diseases and has been also considered as a risk factor for TB reactivation. Pleural TB reactivation, which can occur under anti-TNF therapy, suggests that mycobacteria can survive in this cavity, which thus could be a niche for maintaining living mycobacteria during latent tuberculosis. The understanding of TNF and TNF receptor interactions and the interplay between cells involved in host defense mechanisms in the pleural cavity may help to develop more specific strategies to eliminate mycobacteria and to prevent tuberculosis reactivation.

In conclusion, TNF pathway, but not CCR5, is critical to control pleural BCG infection, regulating inflammatory cytokine and chemokine production, limiting myeloid and lymphoid cell recruitment, and inducing bactericidal mechanisms, thus allowing the control of infection and resolution of inflammatory process.

\section{Supplemental Data}

Supplemental material for this article can be found at http://dx.doi.org/10.1016/j.ajpath.2016.05.015.

\section{References}

1. Dye C, Raviglione M: Perspective: weigh all TB risks. Nature 2013, 502:S13

2. Ferrer J: Pleural tuberculosis. Eur Respir J 1997, 10:942-947

3. Kulchavenya E: Extrapulmonary tuberculosis: are statistical reports accurate? Ther Adv Infect Dis 2014, 2:61-70

4. Antony VB: Immunological mechanisms in pleural disease. Eur Respir J 2003, 21:539-544

5. Russell DG: Who puts the tubercle in tuberculosis? Nat Rev Microbiol 2007, 5:39-47

6. Keane J, Gershon S, Wise RP, Mirabile-Levens E, Kasznica J, Schwieterman WD, Siegel JN, Braun MM: Tuberculosis associated with infliximab, a tumor necrosis factor alpha-neutralizing agent. $\mathrm{N}$ Engl J Med 2001, 345:1098-1104

7. Flynn JL, Chan J: Immunology of tuberculosis. Annu Rev Immunol 2001, 19:93-129

8. Garcia I, Olleros ML, Quesniaux VF, Jacobs M, Allie N, Nedospasov SA, Szymkowski DE, Ryffel B: Roles of soluble and membrane TNF and related ligands in mycobacterial infections: effects of selective and non-selective TNF inhibitors during infection. Adv Exp Med Biol 2011, 691:187-201

9. Allie N, Grivennikov SI, Keeton R, Hsu NJ, Bourigault ML, Court N, Fremond C, Yeremeev V, Shebzukhov Y, Ryffel B, Nedospasov SA, Quesniaux VF, Jacobs M: Prominent role for T cell-derived tumour necrosis factor for sustained control of Mycobacterium tuberculosis infection. Sci Rep 2013, 3:1809

10. Segueni N, Benmerzoug S, Rose S, Gauthier A, Bourigault M-L, Reverchon F, Philippeau A, Erard F, Le Bert M, Bouscayrol H, Wachter T, Garcia I, Kollias G, Jacobs M, Ryffel B, Quesniaux VFJ: Innate myeloid cell TNFR1 mediates first line defence against primary Mycobacterium tuberculosis infection. Sci Rep 2016, 6:22454

11. Garcia I, Olleros ML: The roles of tumor necrosis factor and other macrophage-derived cytokines in host defense mechanisms during the course of mycobacterium tuberculosis infection. Current Topics on The Profiles of Host Immunological Response To Mycobacterial Infections, Chapter 1. Edited by Tomioka H. Trivandrum, India: Research Signpost, 2009. pp. 1-46

12. Dixon WG, Hyrich KL, Watson KD, Lunt M, Galloway J, Ustianowski A; B S R B R Control Centre Consortium, Symmons DP: BSR Biologics Register: Drug-specific risk of tuberculosis in patients with rheumatoid arthritis treated with anti-TNF therapy: results from the British Society for Rheumatology Biologics Register (BSRBR). Ann Rheum Dis 2010, 69:522-528

13. Peto HM, Pratt RH, Harrington TA, LoBue PA, Armstrong LR: Epidemiology of extrapulmonary tuberculosis in the United States, 1993-2006. Clin Infect Dis 2009, 49:1350-1357

14. Kruijshaar ME, Abubakar I: Increase in extrapulmonary tuberculosis in England and Wales 1999-2006. Thorax 2009, 64:1090-1095

15. Forssbohm M, Zwahlen M, Loddenkemper R, Rieder HL: Demographic characteristics of patients with extrapulmonary tuberculosis in Germany. Eur Respir J 2008, 31:99-105

16. Choe H, Farzan M, Sun Y, Sullivan N, Rollins B, Ponath PD, Wu L, Mackay CR, LaRosa G, Newman W, Gerard N, Gerard C, Sodroski J: The beta-chemokine receptors CCR3 and CCR5 facilitate infection by primary HIV-1 isolates. Cell 1996, 85: $1135-1148$

17. Algood HM, Flynn JL: CCR5-deficient mice control Mycobacterium tuberculosis infection despite increased pulmonary lymphocytic infiltration. J Immunol 2004, 173:3287-3296

18. Vesosky B, Rottinghaus EK, Stromberg P, Turner J, Beamer G: CCL5 participates in early protection against Mycobacterium tuberculosis. J Leukoc Biol 2010, 87:1153-1165

19. Antony VB, Sahn SA, Antony AC, Repine JE: Bacillus CalmetteGuerin-stimulated neutrophils release chemotaxins for monocytes in rabbit pleural spaces and in vitro. J Clin Invest 1985, 76: 1514-1521

20. Allen SS, McMurray DN: Coordinate cytokine gene expression in vivo following induction of tuberculous pleurisy in guinea pigs. Infect Immun 2003, 71:4271-4277

21. Menezes-de-Lima-Junior O, Werneck-Barroso E, Cordeiro RS, Henriques MG: Effects of inhibitors of inflammatory mediators and cytokines on eosinophil and neutrophil accumulation induced by Mycobacterium bovis bacillus Calmette-Guerin in mouse pleurisy. $\mathrm{J}$ Leukoc Biol 1997, 62:778-785

22. D'Avila H, Roque NR, Cardoso RM, Castro-Faria-Neto HC, Melo RC, Bozza PT: Neutrophils recruited to the site of Mycobacterium bovis BCG infection undergo apoptosis and modulate lipid body biogenesis and prostaglandin E production by macrophages. Cell Microbiol 2008, 10:2589-2604 
23. Souza MC, Penido C, Costa MFS, Henriques MG: Mechanisms of Tlymphocyte accumulation during experimental pleural infection induced by Mycobacterium bovis BCG. Infect Immun 2008, 76:5686-5693

24. Marino MW, Dunn A, Grail D, Inglese M, Noguchi Y, Richards E, Jungbluth A, Wada H, Moore M, Williamson B, Basu S, Old LJ: Characterization of tumor necrosis factor-deficient mice. Proc Natl Acad Sci U S A 1997, 94:8093-8098

25. Olleros ML, Vesin D, Bisig R, Santiago-Raber ML, SchuepbachMallepell S, Kollias G, Gaide O, Garcia I: Membrane-bound TNF induces protective immune responses to $\mathrm{M}$. bovis $\mathrm{BCG}$ infection: regulation of memTNF and TNF receptors comparing two memTNF molecules. PLoS One 2012, 7:e31469

26. Mubarak KK, Montes-Worboys A, Regev D, Nasreen N, Mohammed KA, Faruqi I, Hensel E, Baz MA, Akindipe OA, Fernandez-Bussy S, Nathan SD, Antony VB: Parenchymal trafficking of pleural mesothelial cells in idiopathic pulmonary fibrosis. Eur Respir J 2012, 39:133-140

27. Segueni N, Vigne S, Palmer G, Bourigault M-L, Olleros ML, Vesin D, Garcia I, Ryffel B, Quesniaux VFJ, Gabay C: Limited contribution of IL-36 versus IL-1 and TNF pathways in host response to mycobacterial infection. PLoS One 2015, 10:e0126058

28. Allie N, Keeton R, Court N, Abel B, Fick L, Vasseur V, Vacher R, Olleros ML, Drutskaya MS, Guler R, Nedospasov SA, Garcia I, Ryffel B, Quesniaux VF, Jacobs M: Limited role for lymphotoxin \{alpha\} in the host immune response to Mycobacterium tuberculosis. J Immunol 2010, 185:4292-4301

29. Antony VB, Mohammed KA: Pathophysiology of pleural space infections. Semin Respir Infect 1999, 14:9-17

30. Valdes L, Pose A, San Jose E, Martinez Vazquez JM: Tuberculous pleural effusions. Eur J Intern Med 2003, 14:77-88

31. Garcia I, Guler R, Vesin D, Olleros ML, Vassalli P, Chvatchko Y, Jacobs M, Ryffel B: Lethal Mycobacterium bovis Bacillus Calmette Guerin infection in nitric oxide synthase 2-deficient mice: cell-mediated immunity requires nitric oxide synthase 2. Lab Invest 2000, 80:1385-1397

32. Zganiacz A, Santosuosso M, Wang J, Yang T, Chen L, Anzulovic M, Alexander S, Gicquel B, Wan Y, Bramson J, Inman M, Xing Z: TNFalpha is a critical negative regulator of type 1 immune activation during intracellular bacterial infection. J Clin Invest 2004, 113:401-413

33. Dalton DK, Haynes L, Chu CQ, Swain SL, Wittmer S: Interferon gamma eliminates responding CD4 $\mathrm{T}$ cells during mycobacterial infection by inducing apoptosis of activated CD4 T cells. J Exp Med 2000, 192:117-122

34. Vig M, Srivastava S, Kandpal U, Sade H, Lewis V, Sarin A, George A, Bal V, Durdik JM, Rath S: Inducible nitric oxide synthase in T cells regulates T cell death and immune memory. J Clin Invest 2004, 113: $1734-1742$

35. Most J, Neumayer HP, Dierich MP: Cytokine-induced generation of multinucleated giant cells in vitro requires interferon-gamma and expression of LFA-1. Eur J Immunol 1990, 20:1661-1667
36. Bopst M, Garcia I, Guler R, Olleros ML, Rulicke T, Muller M, Wyss S, Frei K, Le Hir M, Eugster HP: Differential effects of TNF and LTalpha in the host defense against M. bovis BCG. Eur J Immunol 2001, 31:1935-1943

37. Lucas R, Tacchini-Cottier F, Guler R, Vesin D, Jemelin S, Olleros ML, Marchal G, Browning JL, Vassalli P, Garcia I: A role for lymphotoxin beta receptor in host defense against Mycobacterium bovis BCG infection. Eur J Immunol 1999, 29:4002-4010

38. Flynn JL, Goldstein MM, Chan J, Triebold KJ, Pfeffer K, Lowenstein CJ, Schreiber R, Mak TW, Bloom BR: Tumor necrosis factor-alpha is required in the protective immune response against Mycobacterium tuberculosis in mice. Immunity 1995, 2:561-572

39. Keeton R, Allie N, Dambuza I, Abel B, Hsu N-J, Sebesho B, Randall P, Burger P, Fick E, Quesniaux VFJ, Ryffel B, Jacobs M: Soluble TNFRp75 regulates host protective immunity against Mycobacterium tuberculosis. J Clin Invest 2014, 124:1537-1551

40. Olleros ML, Guler R, Vesin D, Parapanov R, Marchal G, MartinezSoria E, Corazza N, Pache JC, Mueller C, Garcia I: Contribution of transmembrane tumor necrosis factor to host defense against Mycobacterium bovis bacillus Calmette-Guerin and Mycobacterium tuberculosis infections. Am J Pathol 2005, 166:1109-1120

41. Jenkins SJ, Ruckerl D, Cook PC, Jones LH, Finkelman FD, van Rooijen N, MacDonald AS, Allen JE: Local macrophage proliferation, rather than recruitment from the blood, is a signature of TH2 inflammation. Science 2011, 332:1284-1288

42. Mohammed KA, Nasreen N, Ward MJ, Antony VB: Helper T cell type 1 and 2 cytokines regulate $\mathrm{C}-\mathrm{C}$ chemokine expression in mouse pleural mesothelial cells. Am J Respir Crit Care Med 1999, 159:1653-1659

43. Mohammed KA, Nasreen N, Ward MJ, Mubarak KK, RodriguezPanadero F, Antony VB: Mycobacterium-mediated chemokine expression in pleural mesothelial cells: role of C-C chemokines in tuberculous pleurisy. J Infect Dis 1998, 178:1450-1456

44. Mohammed KA, Nasreen N, Hardwick J, Van Horn RD, Sanders KL, Antony VB: Mycobacteria induces pleural mesothelial permeability by down-regulating beta-catenin expression. Lung 2003, 181:57-66

45. Hiroshima K, Yusa T, Kameya T, Ito I, Kaneko K, Kadoyama C, Kishi H, Saitoh Y, Ozaki D, Itami M, Iwata T, Iyoda A, Kawai T, Yoshino I, Nakatani Y: Malignant pleural mesothelioma: clinicopathology of 16 extrapleural pneumonectomy patients with special reference to early stage features. Pathol Int 2009, 59:537-545

46. Batra H, Antony VB: Pleural mesothelial cells in pleural and lung diseases. J Thorac Dis 2015, 7:964-980

47. Lin CY, Chen TC, Lu PL, Lai CC, Yang YH, Lin WR, Huang PM, Chen YH: Effects of gender and age on development of concurrent extrapulmonary tuberculosis in patients with pulmonary tuberculosis: a population based study. PLoS One 2013, 8:e63936 